\title{
Raman and IR Spectra of Ice Ih and Ice XI with an Assessment of DFT Methods
}

\author{
Yuan Liu and Lars Ojamäe \\ Journal Article
}

\section{Tweet}

N.B.: When citing this work, cite the original article.

Original Publication:

Yuan Liu and Lars Ojamäe, Raman and IR Spectra of Ice Ih and Ice XI with an Assessment of DFT Methods, Journal of Physical Chemistry B, 2016. 120(42), pp.11043-11051.

http://dx.doi.org/10.1021/acs.jpcb.6b07001

Copyright: American Chemical Society

http://pubs.acs.org/

Postprint available at: Linköping University Electronic Press

http://urn.kb.se/resolve?urn=urn:nbn:se:liu:diva-132452

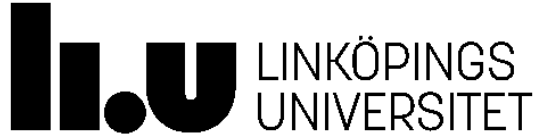




\title{
Raman and IR Spectra of Ice Ih and Ice XI with an Assessment of DFT Methods
}

\author{
Yuan $\mathrm{Liu}^{\dagger}$ and Lars Ojamäe \\ Department of Chemistry, IFM, Linköping University, SE-58 183 Linköping, Sweden \\ † Corresponding author. Phone: +46 13284660 Email address: yuan.liu@liu.se
}

\begin{abstract}
:
IR and Raman spectroscopic technology can be directly used to identify the occurrence of ferroelectric ice XI in laboratory or extraterrestrial settings. The performance of 16 different DFT methods applied on the ice Ih, VIII, IX, and XI crystal phases are evaluated. Based on a selected DFT computational scheme, the IR and Raman spectra of ice Ih and XI are derived and compared. When comparing the spectra of ice Ih and ice XI, both IR and Raman, the librational vibrations are found to be the most affected by the proton ordering. The spectroscopic fingerprint of ice XI can be used to distinguish ferroelectric ice XI from ice Ih in the universe. Furthermore, the existence of only one kind of H-bond in ice Ih is demonstrated from the overlapping sub-spectra for different types of $\mathrm{H}$-bonded pair configurations in 16 isomers of ice Ih, which provides an illustration to the historic debate on whether one or two kinds of H-bonds existed in ice.
\end{abstract}




\section{- INTRODUCTION}

Water is one of the essential natural substances in the universe. The solid phase of water is ice, which have been found in 17 different crystalline structure phases until now. ${ }^{1-16}$ In each phase, the arrangements of oxygen atoms are long-range ordered in a specific symmetry with the hydrogen atoms arranged around the oxygen atoms following the ice rules. ${ }^{17}$ Some of the ice phases are proton-disordered (Ih, ${ }^{1} \mathrm{Ic},{ }^{2} \mathrm{III},{ }^{4} \mathrm{IV},{ }^{5} \mathrm{~V},{ }^{6} \mathrm{VI},{ }^{7} \mathrm{VII},{ }^{8} \mathrm{XII},{ }^{13}$ and $\mathrm{XVI}{ }^{16}$ ) and the others are proton-ordered (II, ${ }^{3} \mathrm{VIII},{ }^{9} \mathrm{IX},{ }^{10} \mathrm{X},{ }^{11} \mathrm{XI},{ }^{12} \mathrm{XIII},{ }^{14} \mathrm{XIV},{ }^{14}$ and $\left.\mathrm{XV}^{15}\right)$.

The ordinary solid phase of water is the proton-disordered ice Ih, the only ice existing on the earth surface. A proton disorder-order transition at low temperatures is known. The proton-ordered phase, ice XI, was discovered from KOH doped ice $\mathrm{Ih}^{18-19}$ and was confirmed to belong to the orthorhombic Cmc $2{ }_{1}$ space group by neutron diffraction. ${ }^{12}$ The ferroelectric character of ice XI was revealed through thermal stimulated depolarization studies. ${ }^{20}$ Ice XI has been suggested to be related with the process of planetary formation as a considerable electric field might be formed from the ferroelectric ice XI in space. ${ }^{21-23}$ Therefore, a lot of effort has been put on ice Ih/XI studies both experimentally and theoretically.

As IR and Raman spectra can be used to study the structure and dynamics of ice, the IR and Raman spectroscopic characteristics of ice Ih have been reported in numerous studies, especially in the $\mathrm{OH}$ stretching vibration region. ${ }^{24-29}$ Only a few works on ice XI have been carried out until now. ${ }^{30-35}$ The polarized Raman spectra of ice XI have been measured based on samples obtained from $\mathrm{KOH}$-doped ice and the vibrational modes in the translational, librational, bending, and stretching region have been assigned by Abe and Shigenari. ${ }^{31-32}$ Comparisons between the spectra of ice Ih and ice XI have been presented in the regions of translational and librational vibrations. ${ }^{30,34}$ The differences between IR spectra of ice Ih and ice XI and the increase of absorbance over a wide frequency range was discussed by Abe and Shigenari. ${ }^{32}$ In parallel to the experimental studies, several theoretical studies have been carried out. ${ }^{36-45}$ The librational modes of ice XI have been studied by density functional theory (DFT) methods and local-MP2 method. ${ }^{39}$ The IR spectra of ice XI were simulated through Car-Parrinello molecular dynamics (CPMD) calculations by Wójcik et al., ${ }^{40}$ who found the significant differences between ice Ih and ice XI in the region of librational vibrations, which was further discussed in a succeeding work. ${ }^{41}$ Earlier, the structure, stability, and phase transition between ice Ih and ice XI have also been studied based on quantumchemical computations. ${ }^{42-45}$

One can envision that IR and Raman spectroscopic measurements could be utilized to determine whether ice XI exist in extraterrestrial situations. To clarify the relation between the planetary formation and ice XI, IR and Raman measurements would be necessary to carry out both in space and in the laboratory. As the growth of a single crystal sample of ice XI suitable for optical measurements is quite difficult, ${ }^{31-32}$ only few studies have carried out for ice XI. At the same time the theoretical studies on the IR and Raman spectra of ice XI are still scarce. To help identify the presence of ferroelectric ice in space, in this work the IR and Raman spectroscopic characteristics of ice Ih/XI according to DFT computations are presented.

\section{- COMPUTATIONAL METHODS}

The unit cell structures of proton-ordered ice VIII, IX, and XI are depicted in Figure 1. The initial lattice parameters and atomic coordinates of ice VIII and IX are taken from 
experimental measurements. ${ }^{9-10}$ The unit cell of ice XI is taken from ref. 42, in which the cell parameters and atomic coordinates of all the possible proton-ordered structures of ice Ih are derived for an orthorhombic cell with 8 water molecules. ${ }^{42}$ Among the 16 unique proton arrangements of an 8-molecule orthorhombic unit cell of ice Ih, the no.1 structure in Ref. 42 is the structure of ice XI. The rather small unit cell was chosen as the base for our vibrational computations since the number of $\mathrm{H}$-bond configurations rapidly increases when doubling or further enlarging the cell. ${ }^{46-47}$

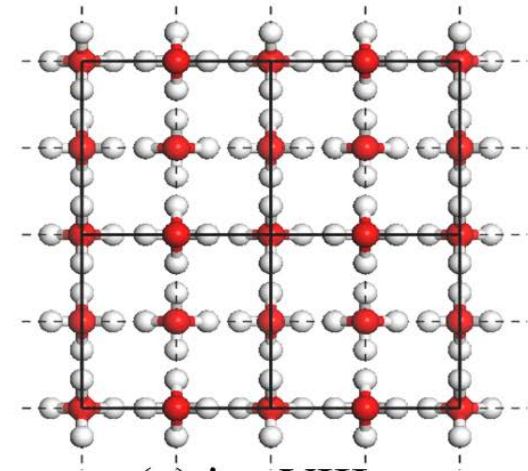

(a) ice VIII

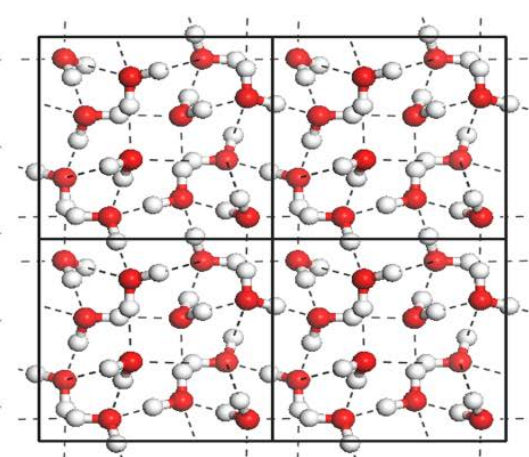

(b) ice IX

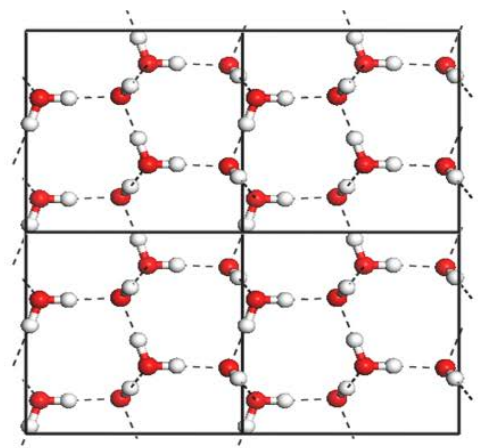

(c) ice XI

Figure 1. The unit cell structures of ice VIII (a), IX (b), and XI (c). The red balls represent oxygen atoms, white balls represent hydrogen atoms, and dashed black lines represent hydrogen bonds.

Due to accurate description of weak interactions (e.g. H-bond and van der Waals interactions) in the DFT framework being a challenge, different exchange-correlation functionals are assessed as in previous studies. ${ }^{48-51}$ The lattice energies and unit cell volumes of ice VIII, IX, and XI are calculated by hybrid (B3LYP, ${ }^{52}$ PBE0, ${ }^{53} \mathrm{HSE03}^{54}$ and HSE06 ${ }^{55}$ ) and general gradient approximation (GGA: PBE, ${ }^{56} \mathrm{RPBE}^{57} \mathrm{PBEsol},{ }^{58} \mathrm{PW} 91,{ }^{59} \mathrm{BLYP},{ }^{60-61}$ and $\mathrm{HCTH}^{62}$ ) functionals, and some of them with dispersion correction (B3LYP-TS, ${ }^{52,} 63$ B3LYP-Grimme, ${ }^{52,64}$ PBE0-TS, ${ }^{53,63}$ PBE-TS, ${ }^{56,63}$ PBE-Grimme, $^{56,64}$ and PW91-OBS ${ }^{59,}{ }^{65}$ ). Except for BLYP and HCTH, the methods are employed using plan-wave basis sets with norm-conserving pseudopotentials in the CASTEP ${ }^{66}$ program in Materials Studio 6.1. The energy cutoff value used is $750 \mathrm{eV}$, the convergence criteria of geometry optimization, SCF, and k-points net used the "fine" set. The BLYP and HCTH methods are employed using the numerical basis sets in $\mathrm{DMol}^{3}$ modulus ${ }^{67-68}$ in Materials Studio 6.1. The "fine" set is used for the convergence tolerance of geometry optimizations, SCF, and k-points nets. The orbital cutoff used is $3.3 \AA$ and the basis set is triple numerical plus polarization (TNP) ${ }^{69}$ basis set. The performance of each functional for the three ice phases is evaluated by comparison with experimental lattice energies and cell volumes. ${ }^{70} \mathrm{PBE}$, PBE-TS, and BLYP/TNP are further checked by studying the lattice energies of the 16 different proton-ordered structures for ice Ih. ${ }^{42}$ Finally, the IR and Raman spectra within the harmonic approximation of the 16 different possible structures of ice Ih are separately simulated using the PBE functional in CASTEP.

For comparison the IR spectrum for ice XI was also calculated using the PBE0 ${ }^{53}$ functional in combination with the large $6-311 \mathrm{G}(2 \mathrm{~d}, 2 \mathrm{p})$ basis set ${ }^{71-72}$ using the CRYSTAL14 program. ${ }^{73-}$ 74 
The spectra of proton-disordered ice Ih is derived by considering the Boltzmann distribution of all the possible proton arrangements satisfying the ice-rules in the 8-molecule unit cell of ice Ih. The Boltzmann-averaged spectra are computed by the aid of the following formula:

$$
p_{i}=\frac{g_{i} e^{-\varepsilon_{i} / k T}}{\sum_{i=1}^{16} g_{i} e^{-\varepsilon_{i} / k T}}
$$

$p_{i}$ is the probability of structure $i, g_{i}$ is the degeneracy of structure $i\left(g_{i}=6,4,4,4,4,4,4,12\right.$, $8,8,8,8,8,8,8,16$ for structure $01-16$, respectively) ${ }^{42}, \varepsilon_{i}$ is the lattice energy of structure $i, k$ is the Boltzmann constant, and $T$ is the temperature which is here set to $273 \mathrm{~K}$. In addition, the $\mathrm{OH}$ stretching vibrations are projected into different categories based on the contributions from different $\mathrm{H}$-bond configurations as in previous studies. ${ }^{75-78}$

\section{- RESULTS AND DISCUSSION}

Assessment of DFT Methods. H-bonding between water molecules is the dominating interaction in ice. The correct descriptions of ice properties depend on accurate calculations of H-bond interactions, which however pose a challenge for DFT methods. Recently, several benchmark DFT studies have been carried out on various phases of ice, and different kinds of DFT methods have been employed in previous studies on ice, ${ }^{49-51,79-84}$ but no one functional has been commonly the preferred choice in the studies of ice. Thus, we evaluated the performance of 16 different DFT methods on ice Ih, VIII, IX, and XI.

Table 1. The lattice energy per molecule of ice VIII, IX, and XI without/with cell parameters kept fixed at the experimental values $(\mathrm{a}=\mathrm{b}=4.68 \AA, \mathrm{c}=6.80 \AA$ for ice VIII in ref. $85, \mathrm{a}=\mathrm{b}=6.73 \AA$, $c=6.73 \AA$ for ice IX in ref. 10 , and $a=4.49, b=7.78, c=7.34$ for ice XI in ref. 86) in the geometry optimization. unit: $\mathrm{kcal} / \mathrm{mol}$

\begin{tabular}{|c|c|c|c|c|c|c|c|c|c|}
\hline & Expt. & B3LYP & $\begin{array}{c}\text { B3LYP- } \\
\text { TS }\end{array}$ & $\begin{array}{c}\text { B3LYP- } \\
\text { Grimme }\end{array}$ & PBE0 & $\begin{array}{c}\text { PBE0- } \\
\text { TS }\end{array}$ & PBE & PBE-TS & $\begin{array}{c}\text { PBE- } \\
\text { Grimme }\end{array}$ \\
\hline VIII & $13.3^{a}$ & $9.1 / 8.6$ & $14.8 / 14.8$ & $15.6 / 15.5$ & $10.7 / 10.6$ & $14.1 / 14.2$ & $10.8 / 10.6$ & $14.5 / 14.4$ & $15.5 / 15.4$ \\
\hline IX & $14.0^{a}$ & $11.9 / 11.8$ & $15.2 / 15.1$ & $15.8 / 15.7$ & $15.8 / 13.3$ & $15.8 / 15.7$ & $14.1 / 13.9$ & $16.7 / 16.5$ & $16.8 / 16.6$ \\
\hline XI & $14.1^{a, b}$ & $13.0 / 13.0$ & $15.3 / 15.3$ & $16.1 / 16.0$ & $14.3 / 14.2$ & $16.0 / 15.7$ & $15.1 / 15.0$ & $17.0 / 16.7$ & $17.5 / 17.1$ \\
\hline & Expt. & RPBE & PBEsol & PW91 & $\begin{array}{c}\text { PW91- } \\
\text { OBS }\end{array}$ & HSE03 & HSE06 & BLYP & HCTH \\
\hline VIII & $13.3^{a}$ & $6.9 / 4.9$ & $14.3 / 14.2$ & $11.3 / 11.1$ & $25.0 / 22.5$ & $10.6 / 10.4$ & $10.5 / 10.3$ & $12.9 / 12.4$ & $11.1 / 8.7$ \\
\hline IX & $14.0^{a}$ & $10.3 / 9.7$ & $17.3 / 16.9$ & $14.7 / 14.5$ & $24.4 / 22.1$ & $13.1 / 13.1$ & $13.0 / 13.0$ & $14.1 / 14.0$ & $12.9 / 12.6$ \\
\hline XI & $14.1^{a, b}$ & $11.3 / 11.2$ & $18.5 / 17.7$ & $15.8 / 15.7$ & $24.0 / 21.6$ & $14.4 / 14.3$ & $14.2 / 14.2$ & $14.9 / 14.9$ & $13.2 / 13.2$ \\
\hline
\end{tabular}

${ }^{a}$ Reference 50 and $70,{ }^{b}$ Reference 87.

The lattice energy per molecule of ice VIII, IX, and XI was calculated by B3LYP, PBE0, HSE03, HSE06, PBE, RPBE, PBEsol, PW91, B3LYP-TS, B3LYP-Grimme, PBE0-TS, PBETS, PBE-Grimme, and PW91-OBS with plane-wave methods in CASTEP, and BLYP and HCTH with TNP basis set in $\mathrm{DMol}^{3}$. As listed in Table 1, two types of computational schemes were applied: in one group, the unit cell of each structure is optimized with the lattice parameters fixed at the experimental values $\left(a=b=4.68 \AA, c=6.80 \AA\right.$ for ice VIII, ${ }^{85}$ $\mathrm{a}=\mathrm{b}=6.73 \AA, \mathrm{c}=6.73 \AA$ for ice $\mathrm{IX},{ }^{10}$ and $\mathrm{a}=4.49, \mathrm{~b}=7.78, \mathrm{c}=7.34$ for ice $\mathrm{XI}^{86}$ ) at zero pressure, whereas in the other group both the cell and atomic coordinates are fully relaxed. In Table 1 and Figure 2, the lattice energies obtained using different functionals are shown. From Figure 2a, we can see that PBE0-TS, PBE-TS, PBEsol, and BLYP work well for ice VIII, where the 
error is less than $1.2 \mathrm{kcal} / \mathrm{mol}$ in comparison with the experimental result, ${ }^{50,70}$ and BLYP performs best (underestimation by $0.4 \mathrm{kcal} / \mathrm{mol}$ ). It was unexpected that B3LYP could show such bad performance for ice VIII with a $4.2 \mathrm{kcal} / \mathrm{mol}$ underestimation. After addition of dispersion correction, the performances of B3LYP, PBE0, and PBE are notably improved, indicating that the dispersion interactions become important in high-density ice. The computational schemes with the worst performances is RPBE with a $6.4 \mathrm{kcal} / \mathrm{mol}$ underestimation and PW91-OBS with an $11.7 \mathrm{kcal} / \mathrm{mol}$ overestimation. For ice IX, PBE, PW91, HSE03, HSE06, and BLYP perform excellent with the error less than $1.0 \mathrm{kcal} / \mathrm{mol}$ compared to the experimental value, ${ }^{50,70}$ in which PBE and BLYP are particularly good with an error of $0.1 \mathrm{kcal} / \mathrm{mol}$. As shown in Figure 2b, for ice IX RPBE and PW91-OBS are also the worst choices with a $3.7 \mathrm{kcal} / \mathrm{mol}$ underestimation and a $10.4 \mathrm{kcal} / \mathrm{mol}$ overestimation, respectively. For ice XI (see Figure 2c), PBE0, PBE, HSE03, HSE06, BLYP, and HCTH perform with errors less than $1.0 \mathrm{kcal} / \mathrm{mol}$ compared to experimental data. ${ }^{50,70,87} \mathrm{RPBE}$ and PW91-OBS are still the worst computational schemes. Hence, for the lattice energy BLYP combined with the TNP basis set perform best with the average absolute error 3.13\% for all the three ice phases. Compared to the other schemes, B3LYP-TS and PBE0-TS perform well with average absolute errors of $9.5 \%$ and $10.8 \%$, respectively. However, the method that is best at predicting the energy differences between the ices is B3LYP with the TS dispersion correction scheme. Considering the unit cell volumes in Table 2, the average absolute errors by BLYP, B3LYP-TS, and PBE0-TS are 5.0\%, 4.1\%, and 8.1\%, respectively, compared to the experimental results. ${ }^{10,12,85-86,88-89}$ 

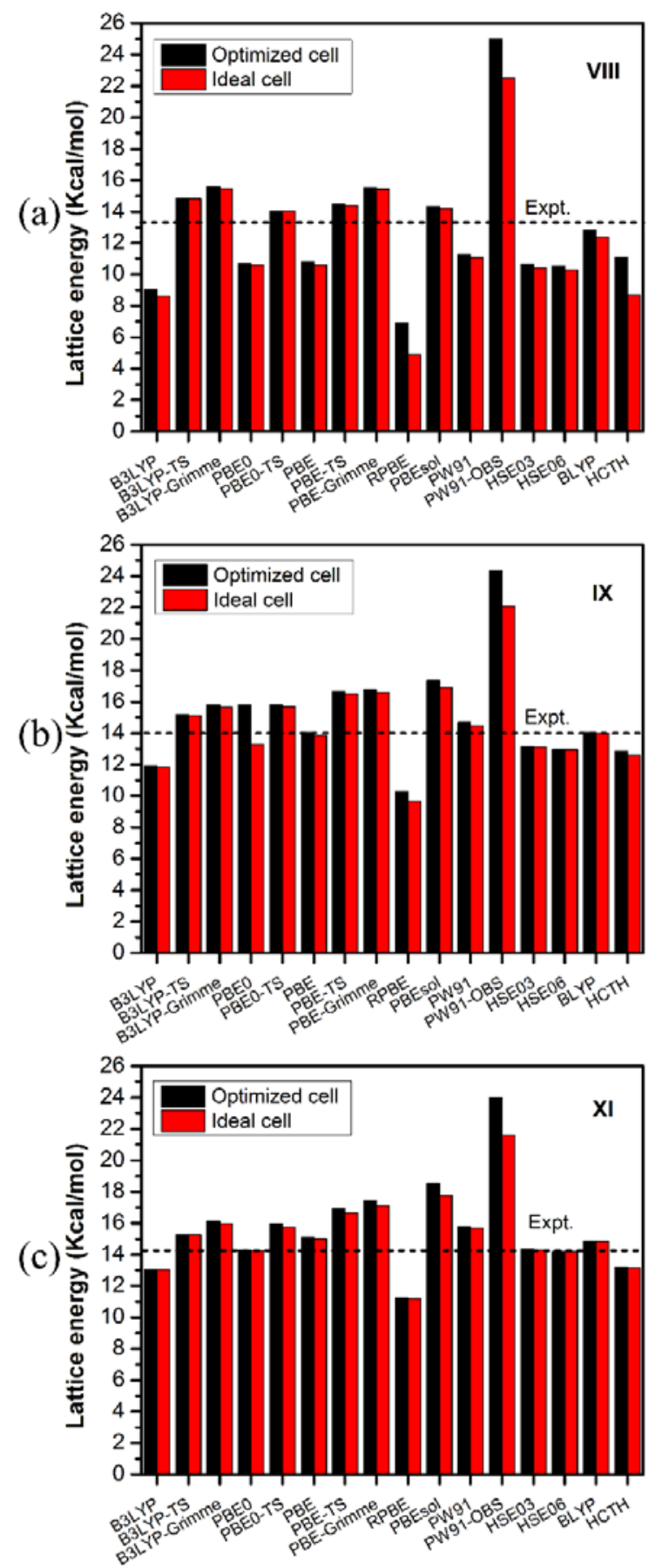

Figure 2. The lattice energies of ice VIII, IX, and XI calculated using different DFT methods. Note: ideal cell means the unit cell optimized with the lattice parameters fixed at the experimental values. 
Table 2. The unit cell volumes per molecule of ice VIII, IX, and XI. unit: $\AA^{3}$

\begin{tabular}{|c|c|c|c|c|c|c|c|c|c|}
\hline & Expt. & B3LYP & $\begin{array}{c}\text { B3LYP- } \\
\text { TS }\end{array}$ & $\begin{array}{c}\text { B3LYP- } \\
\text { Grimme }\end{array}$ & PBE0 & $\begin{array}{c}\text { PBE0- } \\
\text { TS }\end{array}$ & PBE & $\begin{array}{c}\text { PBE- } \\
\text { TS }\end{array}$ & $\begin{array}{c}\text { PBE- } \\
\text { Grimme }\end{array}$ \\
\hline VIII & $18.6^{a}, 20.1^{b}$ & 21.5 & 18.6 & 17.5 & 19.8 & 19.8 & 20.5 & 20.0 & 17.7 \\
\hline IX & $25.6^{c}, 25.8^{d}$ & 27.0 & 23.9 & 23.9 & 23.9 & 23.2 & 27.0 & 23.7 & 23.5 \\
\hline XI & $32.0^{e}, 32.2^{f}$ & 32.1 & 30.2 & 30.2 & 30.2 & 29.3 & 30.3 & 29.2 & 29.0 \\
\hline & Expt. & RPBE & PBEsol & PW91 & $\begin{array}{c}\text { PW91- } \\
\text { OBS }\end{array}$ & HSE03 & HSE06 & BLYP & HCTH \\
\hline VIII & $18.6^{a}, 20.1^{b}$ & 26.0 & 17.6 & 20.1 & 14.3 & 20.3 & 21.5 & 20.7 & 27.4 \\
\hline IX & $25.6^{c}, 25.8^{d}$ & 30.8 & 24.1 & 26.8 & 19.1 & 27.0 & 25.4 & 24.9 & 28.7 \\
\hline XI & $32.0^{e}, 32.2^{f}$ & 33.8 & 27.5 & 30.0 & 24.8 & 30.2 & 32.1 & 31.7 & 33.2 \\
\hline
\end{tabular}

${ }^{a}$ Reference 85, ${ }^{b}$ Reference 88, ${ }^{c}$ Reference 89, ${ }^{d}$ Reference $10,{ }^{e}$ Reference 86, ${ }^{f}$ Reference 12.

BLYP/TNP, PBE, and PBE-TS methods are further evaluated based on the 16 different proton-ordered structures of ice Ih. The lattice energies of each structure are listed in Table 3. As shown in Figure 3, the trends of the energies of the 16 structures is consistent with the previous quantum-chemical studies, ${ }^{42-43,90-91}$ which also observed negligible functional dependence of the relative energies for the different polymorphs for both a cell with fixed dimensions and for fully optimized cells. ${ }^{42-43}$ As shown in Table S1, the cell parameters from BLYP are close to the parameters of the experimental cell values ( $a=4.4974 \AA$ and $c=$ $7.3236 \AA$ ) at $5 \mathrm{~K}^{86}$

To provide an appropriate comparison with the experimental results, the Boltzmannaveraged lattice energy of ice Ih is computed. The results from BLYP, PBE and PBE-TS overestimate the lattice energy by $0.7 \mathrm{kcal} / \mathrm{mol}, 1.0 \mathrm{kcal} / \mathrm{mol}$ and $2.8 \mathrm{kcal} / \mathrm{mol}$, respectively, in comparison with experiment. The energy difference between ice Ih and XI is $0.05 \mathrm{kcal} / \mathrm{mol}$ as obtained by the BLYP/TNP computations, which is very close to the value $(0.06 \mathrm{kcal} / \mathrm{mol})$ estimated from experimental data by Johari. ${ }^{87}$

(a)

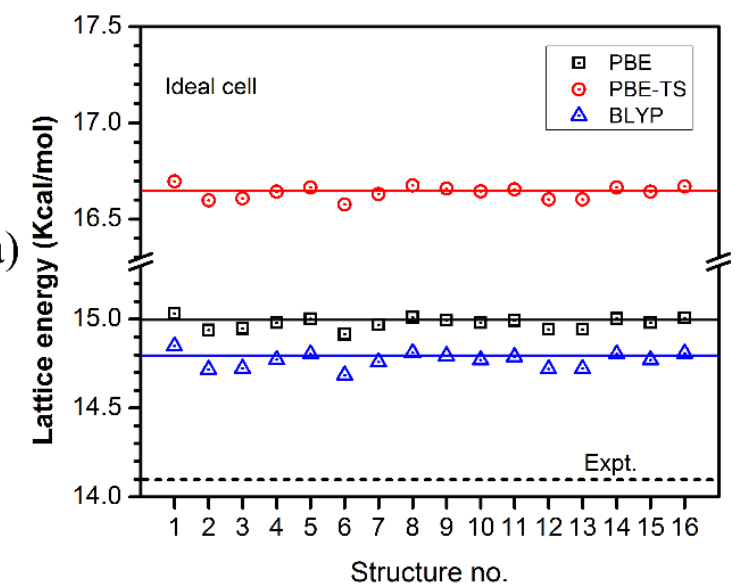

(b)

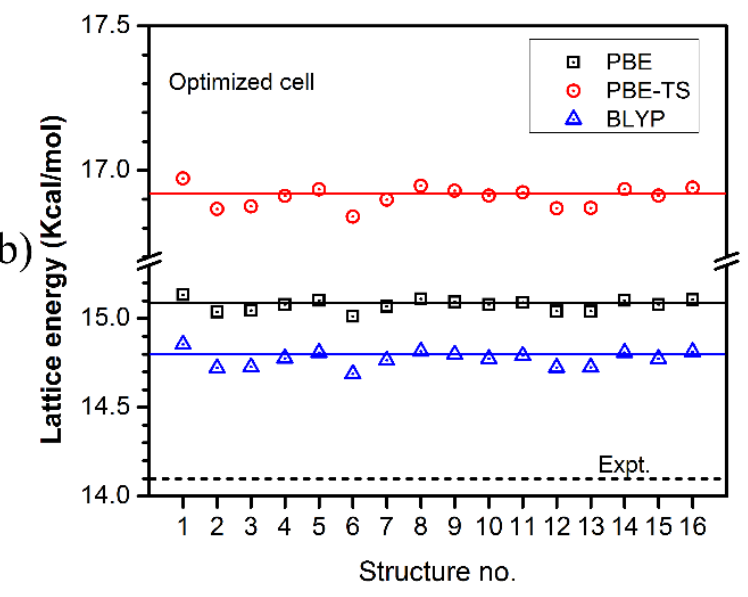

Figure 3. The lattice energies of 16 unique structures of ice Ih calculated by PBE, PBE-TS, and BLYP/TNP. The solid lines represent the Boltzmann-averaged values for the 8-molecule unit cell. 
Table 3. The lattice energy per molecule of the geometry-optimized 16 distinct proton-ordered structures of ice Ih without/with cell parameters fixed at the values from Ref. 42 termed "ideal values”. unit: $\mathrm{kcal} / \mathrm{mol}$

\begin{tabular}{|c|c|c|c|c|c|c|c|c|c|c|c|}
\hline 7 & s01 & $\mathrm{s} 02$ & s03 & s04 & s05 & s06 & s07 & s08 & Ih & $\mathrm{XI}$ & Expt. \\
\hline PBE & $\begin{array}{l}15.13 / \\
15.03\end{array}$ & $\begin{array}{c}15.04 / \\
14.94\end{array}$ & $\begin{array}{l}15.05 / \\
14.95\end{array}$ & $\begin{array}{c}15.08 / \\
14.98\end{array}$ & $\begin{array}{c}15.10 / \\
15.00\end{array}$ & $\begin{array}{l}15.01 / \\
14.92\end{array}$ & $\begin{array}{l}15.07 / \\
14.97\end{array}$ & $\begin{array}{c}15.11 / \\
15.01\end{array}$ & 15.09 & 15.13 & $14.1^{a}$ \\
\hline PBE-TS & $\begin{array}{c}16.97 / \\
16.70\end{array}$ & $\begin{array}{l}16.87 / \\
16.60\end{array}$ & $\begin{array}{l}16.88 / \\
16.61\end{array}$ & $\begin{array}{c}16.91 / \\
16.64\end{array}$ & $\begin{array}{l}16.93 / \\
16.67\end{array}$ & $\begin{array}{c}16.84 / \\
16.58\end{array}$ & $\begin{array}{l}16.90 / \\
16.63\end{array}$ & $\begin{array}{c}16.95 / \\
16.68\end{array}$ & 16.93 & 16.97 & - \\
\hline BLYP & $\begin{array}{l}14.85 / \\
14.85\end{array}$ & $\begin{array}{l}14.72 / \\
14.72\end{array}$ & $\begin{array}{l}14.73 / \\
14.72\end{array}$ & $\begin{array}{l}14.78 / \\
14.77\end{array}$ & $\begin{array}{l}14.81 / \\
14.80\end{array}$ & $\begin{array}{l}14.69 / \\
14.69\end{array}$ & $\begin{array}{l}14.76 / \\
14.76\end{array}$ & $\begin{array}{l}14.82 / \\
14.81\end{array}$ & 14.80 & 14.85 & - \\
\hline & s09 & $\mathrm{s} 10$ & $\mathrm{~s} 11$ & $\mathrm{~s} 12$ & s13 & s14 & s15 & $\mathrm{s} 16$ & - & - & - \\
\hline PBE & $\begin{array}{l}15.09 / \\
15.00\end{array}$ & $\begin{array}{l}15.08 / \\
14.98\end{array}$ & $\begin{array}{l}15.09 / \\
14.99\end{array}$ & $\begin{array}{l}15.04 / \\
14.94\end{array}$ & $\begin{array}{l}15.04 / \\
14.94\end{array}$ & $\begin{array}{l}15.10 / \\
15.00\end{array}$ & $\begin{array}{l}15.08 / \\
14.98\end{array}$ & $\begin{array}{l}15.11 / \\
15.01\end{array}$ & - & - & - \\
\hline PBE-TS & $\begin{array}{l}16.93 / \\
16.66\end{array}$ & $\begin{array}{l}16.91 / \\
16.64\end{array}$ & $\begin{array}{l}16.92 / \\
16.66\end{array}$ & $\begin{array}{c}16.87 / \\
16.60\end{array}$ & $\begin{array}{l}16.87 / \\
16.60\end{array}$ & $\begin{array}{l}16.94 / \\
16.67\end{array}$ & $\begin{array}{l}16.91 / \\
16.64\end{array}$ & $\begin{array}{c}16.94 / \\
16.67\end{array}$ & - & - & - \\
\hline BLYP & $\begin{array}{l}14.80 / \\
14.79\end{array}$ & $\begin{array}{l}14.77 / \\
14.77\end{array}$ & $\begin{array}{l}14.79 / \\
14.79\end{array}$ & $\begin{array}{l}14.73 / \\
14.72\end{array}$ & $\begin{array}{l}14.73 / \\
14.72\end{array}$ & $\begin{array}{l}14.81 / \\
14.80\end{array}$ & $\begin{array}{l}14.77 / \\
14.77\end{array}$ & $\begin{array}{l}14.81 / \\
14.81\end{array}$ & - & - & - \\
\hline
\end{tabular}

${ }^{a}$ Reference 70.

IR and Raman Spectra of Ice Ih/XI. Although BLYP/TNP presents the best performance of all the functionals assessed, we did not use that in the IR and Raman spectroscopic studies since the intensity of each vibrational mode could not be obtained in $\mathrm{DMol}^{3}$. Good descriptions probably can be given by B3LYP-TS and PBE0-TS, but at a quite high computational cost since these are hybrid functionals. Since PBE exhibited good performance in the calculations for 16 isomers of ice Ih and the dispersion interactions have been found to have little influence on IR spectra in liquid water, ${ }^{92}$ the PBE functional was chosen for the simulations of IR and Raman spectra.

A comparison was made with the IR spectrum obtained using the BPE0 hybrid functional ${ }^{71-}$ ${ }^{72}$ with a Gaussian basis set ${ }^{73-74}$ for the first of the 16 isomers, ice XI, as shown in Figure S1. It can be seen that the librational frequencies happen to be quite insensitive to whether the PBE or PBE0 computational results are used (e.g. the spectrum from the PBE calculation have large-intensity peaks at 972, 1028, $1072 \mathrm{~cm}^{-1}$ whereas from PBE0 at 971, 1029, 1080 $\mathrm{cm}^{-1}$ ). However, the bending vibrations and stretching frequencies obtained from the PBE calculation are red-shifted relative to those from the PBE0 calculation (e.g. PBE 1618, 2890, 2920, 3001, $3002 \mathrm{~cm}^{-1}$ unscaled and PBE0 1682, 3253, 3291, 3353, $3363 \mathrm{~cm}^{-1}$ ). In addition it was checked that the computational level chosen for the PBE calculation was adequate (Figures S2 and S3).

The IR and Raman spectra of 16 isomers of ice Ih were calculated and are presented in Figures S4 and S5. The spectra for the translational, librational, bending, and stretching modes are separately plotted in Figures S4a, S4b, S4c, and S4d for IR, and S5a, S5b, S5c, and S5d for Raman. The 16 different H-bond topologies show distinguishable IR and Raman spectra in the range up to $1700 \mathrm{~cm}^{-1}$, and distinguishable IR spectra also in the high-frequency range. There are no obvious differences in the Raman spectra among 16 different H-bond structures of ice Ih in the $\mathrm{OH}$ stretching region (see Figure S5d), which might suggest the Raman spectra of intramolecular vibrations are only slightly influenced by the topology of the H-bond network. 


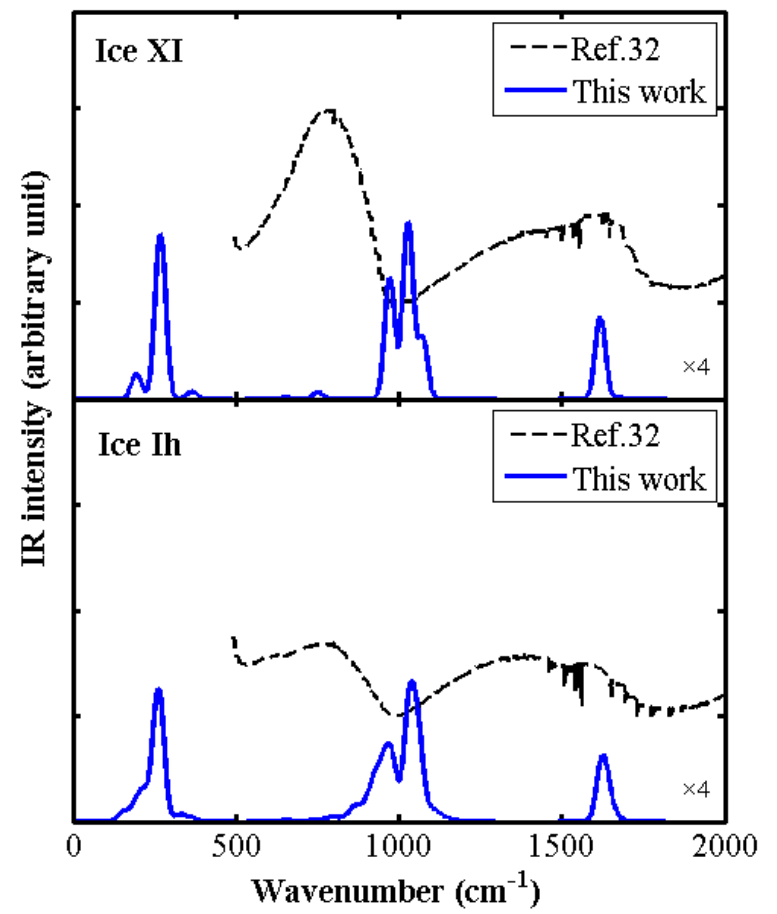

(a)

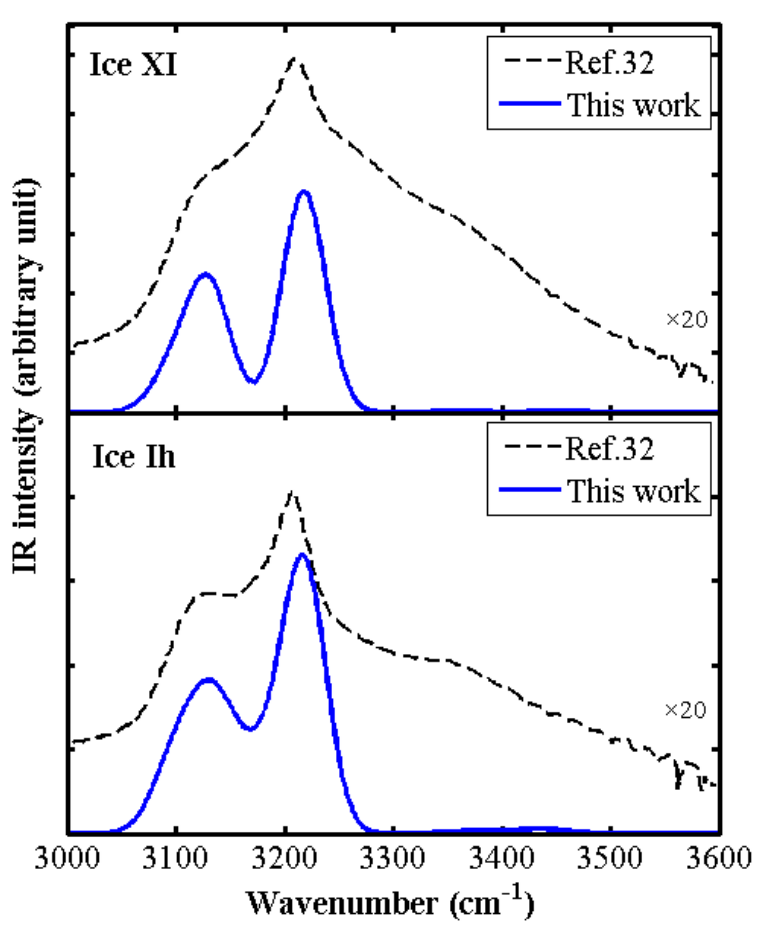

(b)

Figure 4. The IR spectra of ice Ih and XI: (a) the low frequency region and (b) the stretching vibration region. The experimental spectra are extracted from Ref. 32.

The Boltzmann-averaged IR and Raman spectra of ice Ih depicted in Figure 4 and 5, respectively, are derived by introducing the specific weighting factor from the Boltzmann distribution of each isomer. To be able to better compare to the experimentally measured spectra, the stretching frequencies are scaled based on small water cluster results ${ }^{93}$ (see Table S3). As shown in Figures 4 and 5, the computed frequencies are roughly consistent with the experimental measurements. The translational vibrational modes $\left(\boldsymbol{v}_{T}\right)$ are located below 380 $\mathrm{cm}^{-1}$; librational $\left(\boldsymbol{v}_{L}\right)$, bending $\left(\boldsymbol{v}_{B}\right)$, and stretching $\left(\boldsymbol{v}_{S}\right)$ vibrations are located at the range of $650-1190 \mathrm{~cm}^{-1}, 1610-1710 \mathrm{~cm}^{-1}$, and $3090-3460 \mathrm{~cm}^{-1}$, respectively. For the IR spectra (see Figure 4a and 4b), the most obvious difference between ice Ih and XI is that a narrower band and sharper peaks in the librational region are observed for ice XI, which is consistent with previous report by Shigenari and $\mathrm{Abe}^{32}$ and by Wojcik et al. ${ }^{40-41}$ In Figure 5 the Raman spectra of ice Ih and XI are shown. As reported in previous studies, ${ }^{32,34,39}$ also for the Raman spectra the most apparent difference between ice Ih and XI is in the librational region, where several split sharp peaks are found in ice XI as compared to a continuous weak broad band in ice Ih. Thus, the librational modes are more sensitive to the proton ordering, which is a spectroscopic signature that can be used to distinguish ice XI from ice Ih. No obvious difference between ice Ih and XI is found for the $\mathrm{OH}$ stretching part of the spectrum, which might suggest that the intramolecular vibrations are little affected by the proton-ordering. 


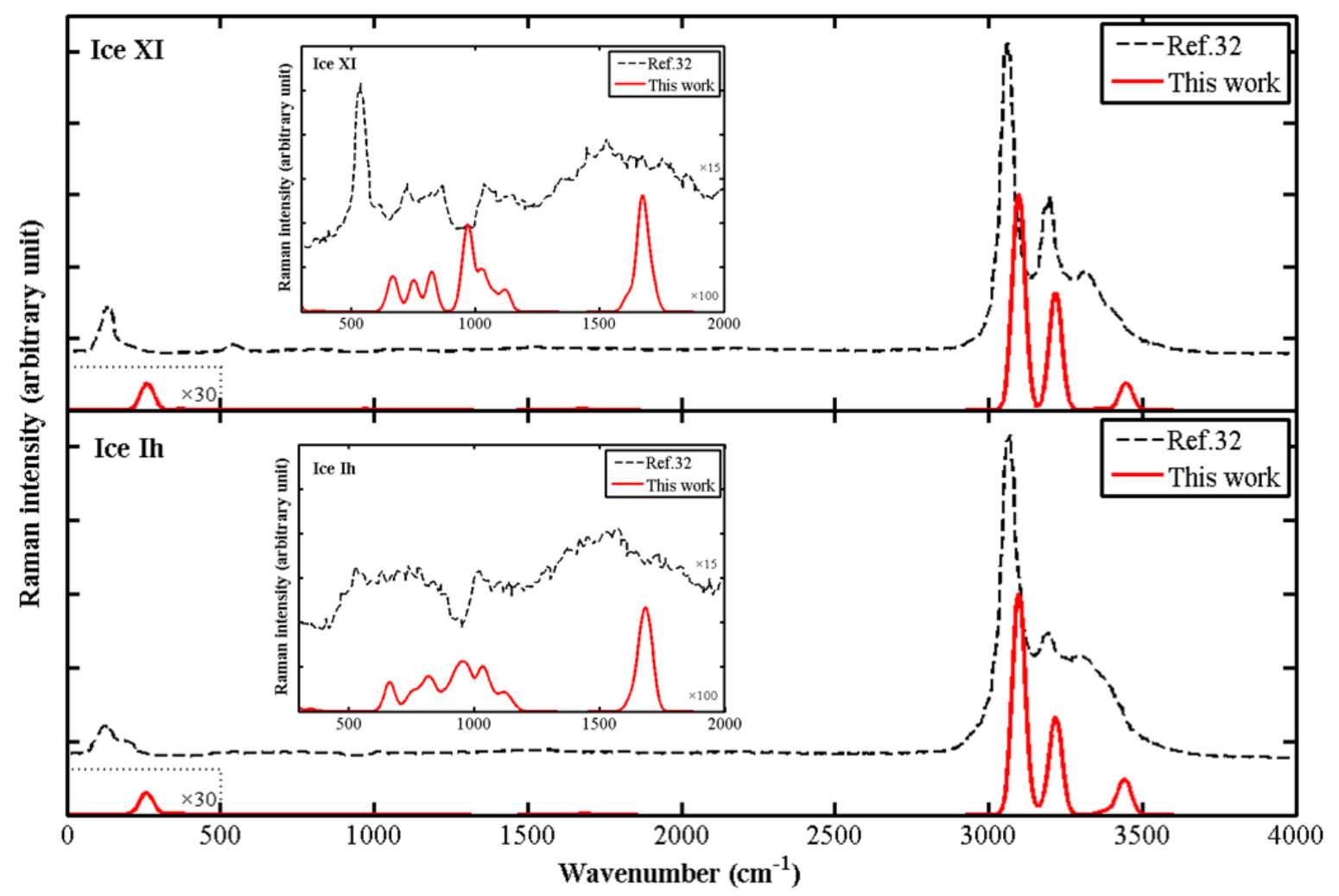

Figure 5. The Raman spectra of ice Ih and XI. Amplifications are shown as inserts.

OH Stretching Vibrations of Ice Ih. The $\mathrm{OH}$ stretching spectra of each ice Ih isomer are split into five different sub-spectra, depicted in Figures 6 and 7. The hydrogen atoms were divided into four different groups based on the types of H-bonded pair configurations A ( $h$ cis), B (h-trans), C (c-cis), and D (c-trans) (see Figure S6) as in previous studies, ${ }^{75-78}$ and the contribution from each group to the total spectra was projected out (in accordance with the number of $\mathrm{H}$ atoms of the group and their vibrational amplitudes squared ${ }^{75-78}$ ). 


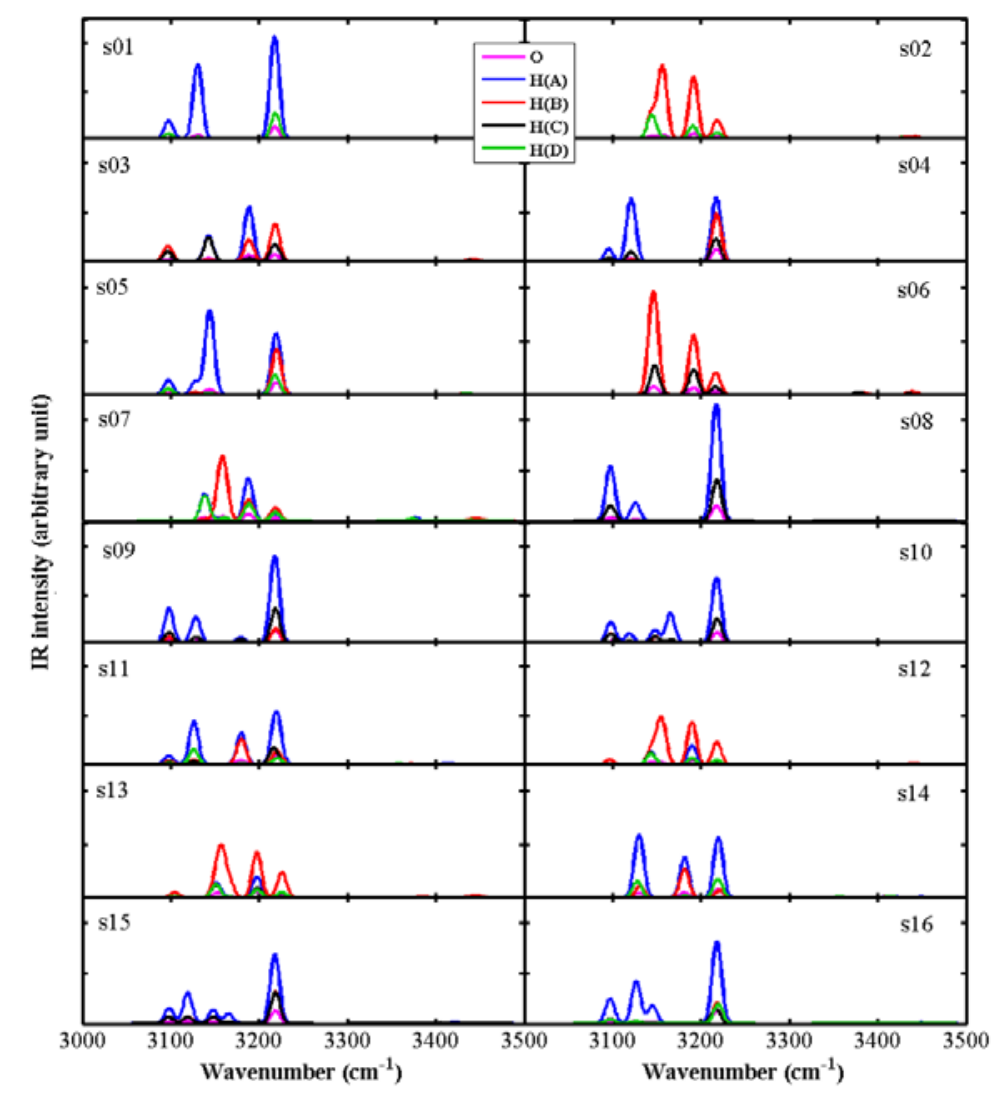

Figure 6. The IR spectra in the $\mathrm{OH}$ stretching region from 16 unique structures of ice Ih split into different sub-spectra based on the specific contributions from each $\mathrm{H}$-bond group (A, B, C, D).

In Figure 6, the IR spectra of stretching vibrations in 16 different isomers of ice Ih are shown in the range of $3090-3460 \mathrm{~cm}^{-1}$. Unlike the distinct distribution of the sub-spectra of each proton group in water clusters, ${ }^{75}, 77$ the sub-spectra in ice overlap in all the 16 cases. This is also observed for the Raman spectra, shown in Figure 7. The $\mathrm{OH}$ stretching vibration is very sensitive to the strength of the H-bond ${ }^{75,77}$ (the Badger-Bauer rule). ${ }^{94-96}$ We see that in ice each of the H-bonded pair configuration essentially contributes to all the peaks in the $\mathrm{OH}$ stretching region. Thus, unlike the existence of different kinds of $\mathrm{H}$-bonds in water clusters (being revealed by the therein separated sub-spectra), ${ }^{75,77}$ there is only one kind of H-bond in ice. This observation provides an illustration to the historic debate on the existence of two kinds of H-bond in ice. ${ }^{97-100}$ 


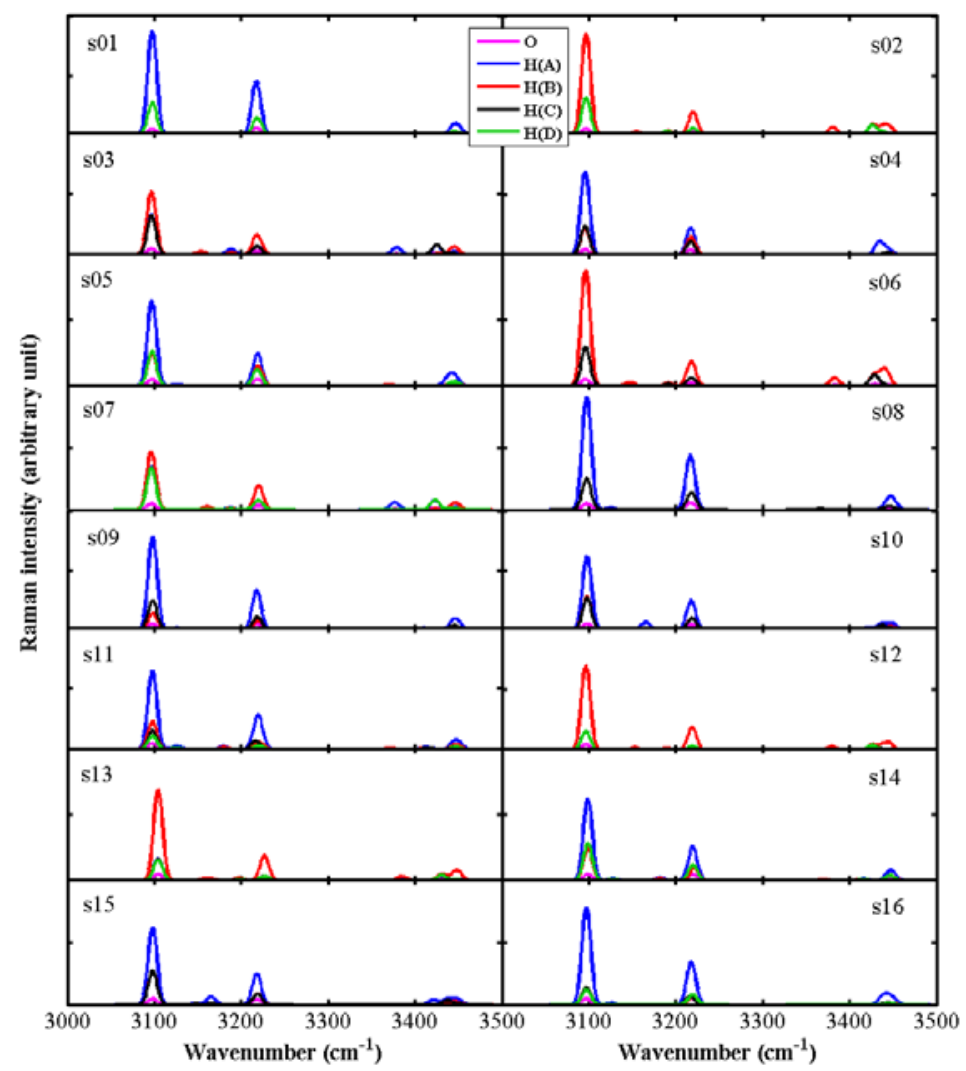

Figure 7. The Raman spectra in the $\mathrm{OH}$ stretching region from 16 unique structures of ice Ih split into different sub-spectra based on the specific contributions from each H-bond group (A, B, C, D).

\section{- CONCLUSIONS}

It is suggested that BLYP combined with TNP basis set is a good method for studies on ice with the average absolute error at 3\% for the energy and 5\% for the volume. B3LYP and PBE0 with the TS dispersion correction can provide an overall fair description of ice with an average absolute error around $10 \%$, as concluded from the present studies on ice VIII, IX, and XI. It is also shown that PBE performs well in studies of 16 different isomers of ice Ih. The IR and Raman spectra of ice Ih and XI are calculated and compared. The librational vibrations are found to be the most affected by the proton ordering from the comparison of both the IR and Raman spectra between ice Ih and XI, in agreement with the measurements by Shigenari and $\mathrm{Abe}^{32}$. This can be used as a spectroscopic fingerprint of ice XI to distinguish ferroelectric ice XI from ice Ih. Furthermore, only one kind ${ }^{99}$ of H-bond, rather than two ${ }^{97-98}$, was observed in ice Ih as concluded from the existence of overlapping sub-spectra for different types of H-bonded pair configurations in 16 isomers of ice Ih.

\section{SUPPORTING INFORMATION}

Optimized unit cell parameters for the 16 proton-ordered structures of ice Ih (Table S1), OH stretching frequencies of water clusters used for calibration (Table S2), Frequencies and IR and Raman intensities for the 16 ice Ih structures using PBE (Table S3, separate text file). IR spectra for ice XI computed using PBE and using PBE0 (Figure S1), IR and Raman PBE spectra for ice XI using different levels of accuracy (Figures S2 and S3), IR and Raman PBE 
spectra of the 16 proton-ordered structures of ice Ih (Figures S4 and S5), the H-bonded neighbor geometries in ice Ih (Figure S6).

\section{ACKNOWLEDGEMENTS}

This work is supported by the Swedish Research Council (VR), the Swedish Supercomputer Center (SNIC/NSC), and a scholarship under the State Scholarship Fund of China Scholarship Council (File No. 201206060016). 


\section{REFERENCES}

1. Fortes, A. D.; Wood, I. G.; Grigoriev, D.; Alfredsson, M.; Kipfstuhl, S.; Knight, K. S.; Smith, R. I. No Evidence for Large-Scale Proton Ordering in Antarctic Ice from Powder Neutron Diffraction. J. Chem. Phys. 2004, 120, 11376-11379.

2. Dowell, L. G.; Rinfret, A. P. Low Temperatre Forms of Ice as Studied by X-ray Diffraction. Nature 1960, 188, 1144-1148.

3. Kamb, B. Ice II: A Proton-Ordered Form of Ice. Acta Crystallogr. 1964, 17, 1437-1449.

4. Kamb, B.; Prakash, A. Structure of Ice III. Acta Cryst. B 1968, 24, 1317-1327.

5. Engelhardt, H.; Kamb, B. Structure of Ice-IV, a Metastable High-Pressure Phase. J. Chem. Phys. 1981, 75 , 5887-5899.

6. Kamb, B.; Prakash, A.; Knobler, C. Structure of Ice V. Acta Crystallogr. 1967, 22, 706-715.

7. Kamb, B. Structure of Ice VI. Science 1965, 150, 205-209.

8. Kamb, B.; Davis, B. L. Ice VII, the Densest Form of Ice. Proc. Natl. Acad. Sci. USA 1964, 52, 1433-1439.

9. Besson, J. M.; Pruzan, P.; Klotz, S.; Hamel, G.; Silvi, B.; Nelmes, R. J.; Loveday, J. S.; Wilson, R. M.; Hull, S. Variation of Interatomic Distances in Ice-VIII to 10 GPa. Phys. Rev. B 1994, 49, 12540-12550.

10. Placa, S. J. L.; Hamilton, W. C. On a Nearly Proton-Ordered Structure for Ice IX. J. Chem. Phys. 1972, 58, 567.

11. Hemley, R. J.; Jephcoat, A. P.; Mao, H. K.; Zha, C. S.; Finger, L. W.; Cox, D. E. Static Compression of $\mathrm{H}_{2} \mathrm{O}$-Ice to $128 \mathrm{GPa}$ (1.28 Mbar). Nature 1987, 330, 737-740.

12. Leadbetter, A. J.; Ward, R. C.; Clark, J. W.; Tucker, P. A.; Matsuo, T.; Suga, H. The Equilibrium LowTemperature Structure of Ice. J. Chem. Phys. 1985, 82, 424-428.

13. Lobban, C.; Finney, J. L.; Kuhs, W. F. The Structure of a New Phase of Ice. Nature 1998, 391, 268-270.

14. Salzmann, C. G.; Radaelli, P. G.; Hallbrucker, A.; Mayer, E.; Finney, J. L. The Preparation and Structures of Hydrogen Ordered Phases of Ice. Science 2006, 311, 1758-1761.

15. Salzmann, C. G.; Radaelli, P. G.; Mayer, E.; Finney, J. L. Ice XV: A New Thermodynamically Stable Phase of Ice. Phys. Rev. Lett. 2009, 103, 105701

16. Falenty, A.; Hansen, T. C.; Kuhs, W. F. Formation and Properties of Ice XVI Obtained by Emptying a Type sII Clathrate Hydrate. Nature 2014, 516, 231-233.

17. Bernal, J. D.; Fowler, R. H. A Theory of Water and Inoic Solution, with Particular Reference to Hydrogen and Hydroxyl Ions. J. Chem. Phys. 1933, 1, 515.

18. Tajima, Y.; Matsuo, T.; Suga, H. Phase-Transition in KOH-Doped Hexagonal Ice. Nature 1982, 299, 810812.

19. Tajima, Y.; Matsuo, T.; Suga, H. Calorimetric Study of Phase-Transition in Hexagonal Ice Doped with Alkali Hydroxides. J. Phys. Chem. Solids 1984, 45, 1135-1144.

20. Jackson, S. M.; Whitworth, R. W. Evidence for Ferroelectric Ordering of Ice Ih. J. Chem. Phys. 1995, 103, 7647-7648.

21. Iedema, M. J.; Dresser, M. J.; Doering, D. L.; Rowland, J. B.; Hess, W. P.; Tsekouras, A. A.; Cowin, J. P. Ferroelectricity in Water Ice. J. Phys. Chem. B 1998, 102, 9203-9214.

22. Wang, H.; Bell, R. C.; Iedema, M. J.; Tsekouras, A. A.; Cowin, J. P. Sticky Ice Grains Aid Planet Formation: Unusual Properties of Cryogenic Water Ice. Astrophys. J. 2005, 620, 1027-1032.

23. Fukazawa, H.; Hoshikawa, A.; Ishii, Y.; Chakoumakos, B. C.; Fernandez-Baca, J. A. Existence of Ferroelectric Ice in the Universe. Astrophys. J. 2006, 652, L57-L60.

24. Li, F.; Skinner, J. L. Infrared and Raman Line Shapes for Ice Ih. I. Dilute HOD in $\mathrm{H}_{2} \mathrm{O}$ and $\mathrm{D}_{2} \mathrm{O}$. J. Chem. Phys. 2010, 132, 204505.

25. Li, F.; Skinner, J. L. Infrared and Raman Line Shapes for Ice Ih. II. $\mathrm{H}_{2} \mathrm{O}$ and $\mathrm{D}_{2} \mathrm{O}$. J. Chem. Phys. 2010, 133, 244504.

26. Wójcik, M. J.; Szczeponek, K.; Ikeda, S. Theoretical Study of the OH/OD Stretching Regions of the Vibrational Spectra of Ice Ih. J. Chem. Phys. 2002, 117, 9850-9857.

27. Bergren, M. S.; Rice, S. A. An Improved Analysis of the OH Stretching Region of the Vibrational-Spectrum of Ice Ih. J. Chem. Phys. 1982, 77, 583-602.

28. Rice, S. A.; Bergren, M. S.; Belch, A. C.; Nielson, G. A Theoretical-Analysis of the OH Stretching Spectra of Ice Ih, Liquid Water, and Amorphous Solid Water. J. Phys. Chem. 1983, 87, 4295-4308.

29. Bertie, J. E.; Whalley, E. Infrared Spectra of Ices Ih and Ic in the Range 4000 to $350 \mathrm{~cm}^{-1}$. J. Chem. Phys. 1964, 40, 1637.

30. Abe, K.; Ishii, K.; Nakajima, M.; Fukuda, H.; Shigenari, T. Raman Scattering at the Proton Ordering Phase Transition in Ice Crystal. Ferroelectrics 2000, 239, 871-878.

31. Abe, K.; Shigenari, T. Raman Spectra of Proton Ordered Phase XI of Ice I. Translational Vibrations Below $350 \mathrm{~cm}^{-1}$. J. Chem. Phys. 2011, 134, 104506. 
32. Shigenari, T.; Abe, K. Vibrational Modes of Hydrogens in the Proton Ordered Phase XI of Ice: Raman Spectra above $400 \mathrm{~cm}^{-1}$. J. Chem. Phys. 2012, 136, 174504.

33. Arakawa, M.; Kagi, H.; Fukazawa, H. Laboratory Measurements of Infrared Absorption Spectra of Hydrogen-Ordered Ice: A Step to the Exploration of Ice XI in Space. Astrophys. J. Suppl. S. 2009, 184, 361-365. 34. Li, J. C.; Nield, V. M.; Jackson, S. M. Spectroscopic Measurements of Ice-XI. Chem. Phys. Lett. 1995, 241, 290-294.

35. Fukazawa, H.; Ikeda, S.; Mae, S. Incoherent Inelastic Neutron Scattering Measurements on Ice XI; the Proton-Ordered Phase of Ice Ih Doped with KOH. Chem. Phys. Lett. 1998, 282, 215-218.

36. Itoh, H.; Kawamura, K.; Hondoh, T.; Mae, S. Molecular Dynamics Studies of Proton Ordering Effects on Lattice Vibrations in Ice Ih. Physica B Condens. Matter. 1996, 219-20, 469-472.

37. Itoh, H.; Kawamura, K.; Hondoh, T.; Mae, S. Polarized Librational Spectra of Proton-Ordered Ice XI by Molecular Dynamics Simulations. J. Chem. Phys. 1998, 109, 4894-4899.

38. Dong, S. L.; Wang, Y.; Li, J. C. Potential Lattice Dynamical Simulations of Ice. Chem. Phys. 2001, 270, 309-317.

39. Erba, A.; Casassa, S.; Dovesi, R.; Maschio, L.; Pisani, C. Periodic Density Functional Theory and LocalMP2 Study of the Librational Modes of Ice XI. J. Chem. Phys. 2009, 130, 074505.

40. Wójcik, M. J.; Gług, M.; Boczar, M.; Boda, Ł. Spectroscopic Signature for Ferroelectric Ice. Chem. Phys. Lett. 2014, 612, 162-166.

41. Gług, M.; Boczar, M.; Boda, Ł.; Wójcik, M. J. Analysis of Librational Modes of Ice XI Studied by CarParrinello Molecular Dynamics. Chem. Phys. 2015, 459, 102-111.

42. Hirsch, T. K.; Ojamäe, L. Quantum-Chemical and Force-Field Investigations of Ice Ih: Computation of Proton-Ordered Structures and Prediction of Their Lattice Energies. J. Phys. Chem. B 2004, 108, 15856-15864.

43. Singer, S. J.; Kuo, J. L.; Hirsch, T. K.; Knight, C.; Ojamäe, L.; Klein, M. L. Hydrogen-Bond Topology and the Ice VII/VIII and Ice Ih/XI Proton-Ordering Phase Transitions. Phys. Rev. Lett. 2005, 94, 135701.

44. Erba, A.; Casassa, S.; Maschio, L.; Pisani, C. DFT and Local-MP2 Periodic Study of the Structure and Stability of Two Proton-Ordered Polymorphs of Ice. J. Phys. Chem. B 2009, 113, 2347-2354.

45. Schonherr, M.; Slater, B.; Hutter, J.; VandeVondele, J. Dielectric Properties of Water Ice, the Ice Ih/XI Phase Transition, and an Assessment of Density Functional Theory. J. Phys. Chem. B 2014, 118, 590-596.

46. Knight, C.; Singer, S. J.; Kuo, J. L.; Hirsch, T. K.; Ojamäe, L.; Klein, M. L. Hydrogen Bond Topology and the Ice VII/VIII and Ih/XI Proton Ordering Phase Transitions. Phys. Rev. E 2006, 73, 056113.

47. Kuo, J. L.; Coe, J. V.; Singer, S. J.; Band, Y. B.; Ojamäe, L. On the Use of Graph Invariants for Efficiently Generating Hydrogen Bond Topologies and Predicting Physical Properties of Water Clusters and Ice. J. Chem. Phys. 2001, 114, 2527-2540.

48. Liu, Y.; Zhao, J. J.; Li, F. Y.; Chen, Z. F. Appropriate Description of Intermolecular Interactions in the Methane Hydrates: An Assessment of Dft Methods. J. Comput. Chem. 2013, 34, 121-131.

49. Kambara, O.; Takahashi, K.; Hayashi, M.; Kuo, J. L. Assessment of Density Functional Theory to Calculate the Phase Transition Pressure of Ice. Phys. Chem. Chem. Phys. 2012, 14, 11484-11490.

50. Brandenburg, J. G.; Maas, T.; Grimme, S. Benchmarking DFT and Semiempirical Methods on Structures and Lattice Energies for Ten Ice Polymorphs. J. Chem. Phys. 2015, 142, 124104.

51. Santra, B.; Klimeš, J.; Tkatchenko, A.; Alfè, D.; Slater, B.; Michaelides, A.; Car, R.; Scheffler, M. On the Accuracy of Van der Waals Inclusive Density-Functional Theory Exchange-Correlation Functionals for Ice at Ambient and High Pressures. J. Chem. Phys. 2013, 139, 154702.

52. Stephens, P. J.; Devlin, F. J.; Chabalowski, C. F.; Frisch, M. J. Ab-initio Calculation of Vibrational Absorption and Circular-Dichroism Spectra Using Density-Functional Force-Fields. J. Phys. Chem. 1994, 98, 11623-11627.

53. Adamo, C.; Barone, V. Toward Reliable Density Functional Methods without Adjustable Parameters: The PBE0 Model. J. Chem. Phys. 1999, 110, 6158-6170.

54. Heyd, J.; Scuseria, G. E.; Ernzerhof, M. Hybrid Functionals Based on a Screened Coulomb Potential. J. Chem. Phys. 2003, 118, 8207-8215.

55. Krukau, A. V.; Vydrov, O. A.; Izmaylov, A. F.; Scuseria, G. E. Influence of the Exchange Screening Parameter on the Performance of Screened Hybrid Functionals. J. Chem. Phys. 2006, 125, 224106.

56. Perdew, J. P.; Burke, K.; Ernzerhof, M. Generalized Gradient Approximation Made Simple. Phys. Rev. Lett. 1996, 77, 3865-3868.

57. Hammer, B.; Hansen, L. B.; Norskov, J. K. Improved Adsorption Energetics within Density-Functional Theory Using Revised Perdew-Burke-Ernzerhof Functionals. Phys. Rev. B 1999, 59, 7413-7421.

58. Perdew, J. P.; Ruzsinszky, A.; Csonka, G. I.; Vydrov, O. A.; Scuseria, G. E.; Constantin, L. A.; Zhou, X. L.; Burke, K. Restoring the Density-Gradient Expansion for Exchange in Solids and Surfaces. Phys. Rev. Lett. 2008, $100,136406$. 
59. Perdew, J. P.; Chevary, J. A.; Vosko, S. H.; Jackson, K. A.; Pederson, M. R.; Singh, D. J.; Fiolhais, C. Atoms, Molecules, Solids, and Surfaces - Applications of the Generalized Gradient Approximation for Exchange and Correlation. Phys. Rev. B 1992, 46, 6671-6687.

60. Becke, A. D. A Multicenter Numerical-Integration Scheme for Polyatomic-Molecules. J. Chem. Phys. 1988, 88, 2547-2553.

61. Lee, C. T.; Yang, W. T.; Parr, R. G. Development of the Colle-Salvetti Correlation-Energy Formula into a Functional of the Electron-Density. Phys. Rev. B 1988, 37, 785-789.

62. Boese, A. D.; Handy, N. C. A New Parametrization of Exchange-Correlation Generalized Gradient Approximation Functionals. J. Chem. Phys. 2001, 114, 5497-5503.

63. Tkatchenko, A.; Scheffler, M. Accurate Molecular Van der Waals Interactions from Ground-State Electron Density and Free-Atom Reference Data. Phys. Rev. Lett. 2009, 102, 073005.

64. Grimme, S. Semiempirical GGA-Type Density Functional Constructed with a Long-Range Dispersion Correction. J. Comput. Chem. 2006, 27, 1787-1799.

65. Ortmann, F.; Bechstedt, F.; Schmidt, W. G. Semiempirical Van der Waals Correction to the Density Functional Description of Solids and Molecular Structures. Phys. Rev. B 2006, 73, 205101.

66. Clark, S. J.; Segall, M. D.; Pickard, C. J.; Hasnip, P. J.; Probert, M. J.; Refson, K.; Payne, M. C. First Principles Methods Using CASTEP. Z. Kristallogr. 2005, 220, 567-570.

67. Delley, B. An All-Electron Numerical-Method for Solving the Local Density Functional for PolyatomicMolecules. J. Chem. Phys. 1990, 92, 508-517.

68. Delley, B. From Molecules to Solids with the Dmol ${ }^{3}$ Approach. J. Chem. Phys. 2000, 113, 7756-7764.

69. Delley, B. Ground-State Enthalpies: Evaluation of Electronic Structure Approaches with Emphasis on the Density Functional Method. J. Phys. Chem. A 2006, 110, 13632-13639.

70. Whalley, E. Energies of the Phases of Ice at Zero Temperature and Pressure. J. Chem. Phys. 1984, 81, 40874092.

71. McLean, A. D.; Chandler, G. S. Contracted Gaussian-Basis Sets for Molecular Calculations .I. Second Row Atoms, Z=11-18. J. Chem. Phys. 1980, 72, 5639-5648.

72. Krishnan, R.; Binkley, J. S.; Seeger, R.; Pople, J. A. Self-Consistent Molecular-Orbital Methods .XX. A Basis Set for Correlated Wave-Functions. J. Chem. Phys. 1980, 72, 650-654.

73. Dovesi, R.; Orlando, R.; Erba, A.; Zicovich-Wilson, C. M.; Civalleri, B.; Casassa, S.; Maschio, L.; Ferrabone, M.; De La Pierre, M.; D'Arco, P., et al. CRYSTAL14: A Program for the Ab Initio Investigation of Crystalline Solids. Int. J. Quantum Chem. 2014, 114, 1287-1317.

74. Dovesi, R.; Saunders, V. R.; Roetti, C.; Orlando, R.; Zicovich-Wilson, C. M.; Pascale, F.; Civalleri, B.; Doll, K.; Harrison, N. M.; Bush, I. J., et al. CRYSTAL14 User's Manual, University of Torino, Torino, 2014.

75. Liu, Y.; Ojamäe, L. Fingerprints in IR OH Vibrational Spectra of $\mathrm{H}_{2} \mathrm{O}$ Clusters from Different $\mathrm{H}-\mathrm{Bond}$ Conformations by Means of Quantum-Chemical Computations. J. Mol. Model. 2014, 20, 2281.

76. Liu, Y.; Ojamäe, L. C-C Stretching Raman Spectra and Stabilities of Hydrocarbon Molecules in Natural Gas Hydrates: A Quantum Chemical Study. J. Phys. Chem. A 2014, 118, 11641-11651.

77. Liu, Y.; Ojamäe, L. CH-Stretching Vibrational Trends in Natural Gas Hydrates Studied by QuantumChemical Computations. J. Phys. Chem. C 2015, 119, 17084-17091.

78. Lenz, A.; Ojamäe, L. Theoretical IR Spectra for Water Clusters $\left(\mathrm{H}_{2} \mathrm{O}\right)_{\mathrm{N}}(\mathrm{N}=6-22,28,30)$ and Identification of Spectral Contributions from Different H-Bond Conformations in Gaseous and Liquid Water. J. Phys. Chem. A 2006, 110, 13388-13393.

79. Gillan, M. J.; Alfè, D.; Bygrave, P. J.; Taylor, C. R.; Manby, F. R. Energy Benchmarks for Water Clusters and Ice Structures from an Embedded Many-Body Expansion. J. Chem. Phys. 2013, 139, 114101.

80. Macher, M.; Klimeš, J.; Franchini, C.; Kresse, G. The Random Phase Approximation Applied to Ice. J. Chem. Phys. 2014, 140, 084502.

81. Kolb, B.; Thonhauser, T. Van der Waals Density Functional Study of Energetic, Structural, and Vibrational Properties of Small Water Clusters and Ice Ih. Phys. Rev. B 2011, 84, 045116.

82. Santra, B.; Klimeš, J.; Alfè, D.; Tkatchenko, A.; Slater, B.; Michaelides, A.; Car, R.; Scheffler, M. Hydrogen Bonds and Van der Waals Forces in Ice at Ambient and High Pressures. Phys. Rev. Lett. 2011, 107, 185701.

83. Murray, E. D.; Galli, G. Dispersion Interactions and Vibrational Effects in Ice as a Function of Pressure: A First Principles Study. Phys. Rev. Lett. 2012, 108, 105502.

84. Hamada, I. A Van der Waals Density Functional Study of Ice Ih. J. Chem. Phys. 2010, 133, 214503.

85. Jorgensen, J. D.; Beyerlein, R. A.; Watanabe, N.; Worlton, T. G. Structure of $\mathrm{D}_{2} \mathrm{O}$ Ice-VIII from Insitu Powder Neutron-Diffraction. J. Chem. Phys. 1984, 81, 3211-3214.

86. Line, C. M. B.; Whitworth, R. W. A High Resolution Neutron Powder Diffraction Study of $\mathrm{D}_{2} \mathrm{O}$ Ice XI. J. Chem. Phys. 1996, 104, 10008-10013.

87. Johari, G. P. An Interpretation for the Thermodynamic Features of Ice Ih - Ice XI Transformation. J. Chem. Phys. 1998, 109, 9543-9548. 
88. Yoshimura, Y.; Stewart, S. T.; Somayazulu, M.; Mao, H.; Hemley, R. J. High-Pressure X-ray Diffraction and Raman Spectroscopy of Ice VIII. J. Chem. Phys. 2006, 124, 024502.

89. Londono, J. D.; Kuhs, W. F.; Finney, J. L. Neutron-Diffraction Studies of Ice-III and Ice-IX on underPressure and Recovered Samples. J. Chem. Phys. 1993, 98, 4878-4888.

90. Tribello, G. A.; Slater, B. Proton Ordering Energetics in Ice Phases. Chem. Phys. Lett. 2006, 425, $246-250$.

91. Raza, Z.; Alfè, D.; Salzmann, C. G.; Klimeš, J.; Michaelides, A.; Slater, B. Proton Ordering in Cubic Ice and Hexagonal ice; A Potential New Ice Phase - XIc. Phys. Chem. Chem. Phys. 2011, 13, 19788-19795.

92. Akin-Ojo, O.; Wang, F. Effects of the Dispersion Interaction in Liquid Water. Chem. Phys. Lett. 2011, 513, 59-62.

93. Huisken, F.; Kaloudis, M.; Kulcke, A. Infrared Spectroscopy of Small Size-Selected Water Clusters. J. Chem. Phys. 1996, 104, 17-25.

94. Badger, R. M.; Bauer, S. H. Spectroscopic Studies of the Hydrogen Bond. II. The Shift of the OH Vibrational Frequency in the Formation of the Hydrogen Bond. J. Chem. Phys. 1937, 5, 839-851.

95. Huggins, C. M.; Pimentel, G. C. Systematics of the Infrared Spectral Properties of Hydrogen Bonding Systems: Frequency Shift, Half Width and Intensity. J. Phys. Chem. 1956, 60, 1615-1619.

96. Mecke, R. Infra-Red Spectra of Hydroxylic Compounds. Discuss. Faraday Soc. 1950, 9, 161-177.

97. Li, J. C.; Ross, D. K. Evidence for Two Kinds of Hydrogen-Bond in Ice. Nature 1993, 365, 327-329.

98. Li, J. C.; Bennington, S. M.; Ross, D. K. Further Evidence for the Existence of Two Kinds of H-Bonds in Ice Ih. Phys. Lett. A 1994, 192, 295-300.

99. Tse, J. S.; Klug, D. D. Further Evidence for the Existence of Two Kinds of H-Bonds in Ice Ih - Comments. Phys. Lett. A 1995, 198, 464-466.

100. He, X.; Sode, O.; Xantheas, S. S.; Hirata, S. Second-Order Many-Body Perturbation Study of Ice Ih. J. Chem. Phys. 2012, 137, 204505. 
Table of Contents Image

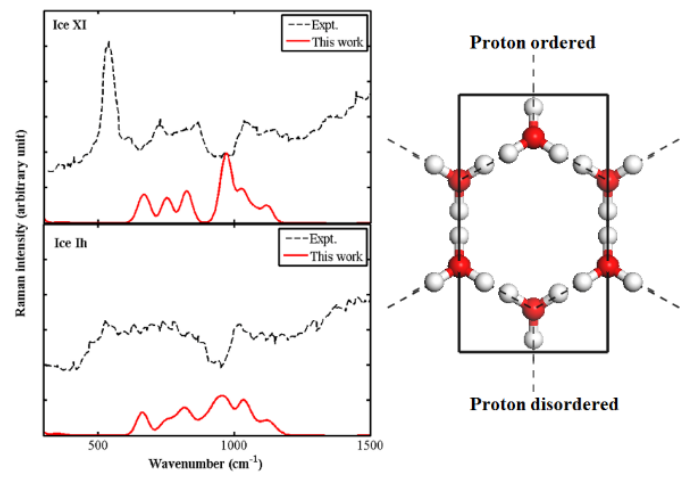




\title{
Raman and IR Spectra of Ice Ih and ice XI with an Assessment of DFT Methods
}

\author{
Yuan $\mathrm{Liu}^{\dagger}$ and Lars Ojamäe \\ Department of Chemistry, IFM, Linköping University, SE-58 183 Linköping, Sweden \\ ${ }^{\dagger}$ Corresponding author. Phone: +46 13284660 Email address: yuan.liu@liu.se
}


Table S1. The unit cell parameters of the 16 proton-ordered structures of ice Ih after geometry optimization using PBE, PBE with the TS dispersion correction scheme, and BLYP/TNP.

\begin{tabular}{|c|c|c|c|c|c|c|}
\hline no. & \multicolumn{2}{|c|}{ PBE } & \multicolumn{2}{c|}{ PBE-TS } & \multicolumn{2}{c|}{ BLYP/TNP } \\
\hline s01 & $4.41,7.65,7.20$ & $90,90,90$ & $4.35,7.55,7.11$ & $90,90,90$ & $4.47,7.79,7.29$ & $90,90,90$ \\
\hline s02 & $4.42,7.63,7.21$ & $90,90,90$ & $4.37,7.54,7.11$ & $90,90,90$ & $4.50,7.73,7.31$ & $90,90,90$ \\
\hline s03 & $4.42,7.64,7.21$ & $90,90,90$ & $4.38,7.57,7.13$ & $90,90,90$ & $4.49,7.75,7.30$ & $90,90,90$ \\
\hline s04 & $4.42,7.64,7.21$ & $90,90,90$ & $4.37,7.57,7.14$ & $90,90,90$ & $4.49,7.74,7.31$ & $90,90,90$ \\
\hline s05 & $4.42,7.64,7.21$ & $90,90,90$ & $4.37,7.57,7.13$ & $90,90,90$ & $4.49,7.73,7.30$ & $90,90,90$ \\
\hline s06 & $4.42,7.63,7.21$ & $90,90,90$ & $4.38,7.56,7.14$ & $90,90,90$ & $4.50,7.74,7.31$ & $90,90,90$ \\
\hline s07 & $4.42,7.64,7.20$ & $90,90,90$ & $4.38,7.57,7.13$ & $90,90,90$ & $4.49,7.75,7.30$ & $90,90,90$ \\
\hline s08 & $4.42,7.64,7.21$ & $90,90,90$ & $4.37,7.57,7.13$ & $90,90,90$ & $4.48,7.75,7.30$ & $90,90.3,90$ \\
\hline s09 & $4.41,7.65,7.21$ & $90,90,90$ & $4.37,7.57,7.13$ & $90,90,90$ & $4.48,7.76,7.30$ & $89.4,90,90$ \\
\hline s10 & $4.42,7.65,7.21$ & $90,90,90$ & $4.37,7.57,7.13$ & $90,90,90$ & $4.48,7.76,7.30$ & $90,90,90.1$ \\
\hline s11 & $4.42,7.65,7.21$ & $90,90,90$ & $4.37,7.57,7.13$ & $90,90,90$ & $4.48,7.76,7.30$ & $90,90.2,90$ \\
\hline s12 & $4.42,7.64,7.21$ & $90,90,90$ & $4.38,7.57,7.13$ & $90,90,90$ & $4.49,7.74,7.30$ & $90,90,90$ \\
\hline s13 & $4.43,7.65,7.22$ & $90,90,90$ & $4.38,7.57,7.13$ & $90,90,90$ & $4.50,7.74,7.30$ & $90,90,90$ \\
\hline s14 & $4.42,7.65,7.21$ & $90,90,90$ & $4.37,7.57,7.13$ & $90,90,90$ & $4.48,7.76,7.29$ & $90,90,90.2$ \\
\hline s15 & $4.42,7.65,7.21$ & $90,90,90$ & $4.37,7.57,7.13$ & $90,90,90$ & $4.48,7.76,7.30$ & $90,90.1,90$ \\
\hline s16 & $4.42,7.64,7.21$ & $90,90,90$ & $4.37,7.57,7.13$ & $90,90,90$ & $4.49,7.74,7.30$ & $89.9,90.1,89.7$ \\
\hline
\end{tabular}


Table S2. The bonded $\mathrm{OH}$ stretching frequencies of small water clusters $\left(\mathrm{H}_{2} \mathrm{O}\right)_{2-5}$.

\begin{tabular}{|l|l|l|}
\hline & Calculated & Expt. $^{a}$ \\
\hline$\left(\mathrm{H}_{2} \mathrm{O}\right)_{2}$ & 3457 & 3601 \\
\hline$\left(\mathrm{H}_{2} \mathrm{O}\right)_{3}$ & 3334 & 3533 \\
\hline$\left(\mathrm{H}_{2} \mathrm{O}\right)_{4}$ & 3118 & 3416 \\
\hline$\left(\mathrm{H}_{2} \mathrm{O}\right)_{5}$ & 3049 & 3360 \\
\hline
\end{tabular}

Note: the scaling factor is calculated by the formula $c=\frac{\sum v_{i} \times \omega_{i}}{\sum \omega_{i}{ }^{2}}=1.072, v_{i}$ is the experimentally measured wavenumber and $\omega_{i}$ is the computed wavenumber from this work. ${ }^{a}$ Reference 85. 
Table S3. Computed vibrational frequencies and IR and Raman intensities of ice XI using the PBE functional and the plane wave basis set with an energy cutoff of $750 \mathrm{eV}$. unit: $\mathrm{cm}^{-1}$

\begin{tabular}{|c|c|c|c|c|c|c|}
\hline \multicolumn{3}{|c|}{ Translation Modes } & \multicolumn{4}{|c|}{ Libration Modes } \\
\hline Freq. & IR & Raman & Freq. & & IR & Raman \\
\hline Calc. & Intensity & Intensity & Calc. & & Intensity & Intensity \\
\hline 25.79784 & $2.3 \mathrm{E}-06$ & 0.009684 & 654.2946 & & 0.135585 & 0.325726 \\
\hline 57.85342 & 0 & 0.002598 & 655.9757 & & 0.059538 & 0.183255 \\
\hline 69.52301 & 0 & 0.021451 & 660.489 & & 0 & 0.00023 \\
\hline 93.53978 & 0.01382 & $5 \mathrm{E}-07$ & 661.8796 & & 0 & 1.855892 \\
\hline 98.70972 & 0.009069 & 0.001659 & 677.3546 & & 0.000257 & 2.046775 \\
\hline 130.9715 & $8.26 \mathrm{E}-05$ & 0.000046 & 750.4045 & & $7.94 \mathrm{E}-05$ & 0.000412 \\
\hline 151.9552 & 0.000487 & $1.74 \mathrm{E}-05$ & 751.4869 & & 3.9E-06 & $2.8 \mathrm{E}-06$ \\
\hline 194.5885 & 2.416094 & 0.000399 & 752.6114 & & 0.60627 & 3.54811 \\
\hline 233.6776 & 0.00033 & 0.000247 & 755.5911 & & $1 \mathrm{E}-07$ & 0 \\
\hline 240.3786 & 0.024041 & 0.004737 & 825.0691 & & 0 & 4.489829 \\
\hline 244.5967 & 0.220002 & 0.176837 & 826.6418 & & 0 & 0.00018 \\
\hline 254.1053 & 0 & 2.385633 & 935.5377 & & $4 \mathrm{E}-07$ & $2.9 \mathrm{E}-06$ \\
\hline 257.2154 & 0 & 2.94624 & 942.1517 & & $3.8 \mathrm{E}-06$ & 9E-07 \\
\hline 263.5735 & 6.773433 & 5.470218 & 946.2033 & & 0 & 1.67E-05 \\
\hline 271.6327 & 9.664121 & 1.922544 & 948.0816 & & 0 & 1.354344 \\
\hline 272.921 & 0.019744 & 0.015707 & 949.7798 & & $2.8 \mathrm{E}-06$ & 0 \\
\hline 278.7944 & 0.008462 & 0.042777 & 958.8222 & & $1.7 \mathrm{E}-06$ & 0.000001 \\
\hline 286.3203 & 0.00063 & 0.000129 & 971.9453 & & 11.67128 & 9.101082 \\
\hline 353.1239 & 0.000491 & $2.5 \mathrm{E}-06$ & 1023.866 & & 0 & 9E-07 \\
\hline 365.3615 & 0.659748 & 0.16419 & 1027.73 & & 17.08187 & 4.503886 \\
\hline \multirow[t]{4}{*}{369.7208} & 0.012886 & 0.226748 & 1072.022 & & 5.867577 & 1.948369 \\
\hline & & & 1121.409 & & 0 & 2.384025 \\
\hline & & & 1137.039 & & 0 & 0.000061 \\
\hline & & & 1184.559 & & 0.007981 & 0.00881 \\
\hline \multicolumn{3}{|c|}{ Bending Modes } & \multicolumn{4}{|c|}{ Stretching Modes } \\
\hline Freq. & IR & Raman & Freq. & Freq. & IR & Raman \\
\hline Calc. & Intensity & Intensity & Calc. & Scaled $^{a}$ & Intensity & Intensity \\
\hline 1616.196 & 2.475031 & 1.488379 & 2889.505 & 3097.55 & 68.05285 & 3008.271 \\
\hline 1618.136 & 5.439601 & 0.417496 & 2920.097 & 3130.344 & 211.711 & 18.07486 \\
\hline 1629.207 & $6.7 \mathrm{E}-06$ & $5.3 \mathrm{E}-06$ & 2922.181 & 3132.578 & 0.004325 & 0.000233 \\
\hline 1664.706 & 9E-07 & $2 \mathrm{E}-07$ & 3000.545 & 3216.584 & 0 & 589.1073 \\
\hline 1671.429 & 0.133057 & 12.5386 & 3000.648 & 3216.695 & 0.001242 & 0.001735 \\
\hline 1679.237 & 0 & 0 & 3001.25 & 3217.34 & 221.2878 & 287.7263 \\
\hline 1689.835 & $2 \mathrm{E}-07$ & 4.7E-06 & 3001.361 & 3217.459 & 0.000131 & 0.003547 \\
\hline \multirow[t]{9}{*}{1710.388} & 0.002854 & 3.476039 & 3002.242 & 3218.404 & 136.4268 & 698.748 \\
\hline & & & 3002.47 & 3218.648 & 13.31854 & 68.35083 \\
\hline & & & 3136.769 & 3362.616 & 3.594124 & 18.64096 \\
\hline & & & 3137.462 & 3363.359 & $2.07 \mathrm{E}-05$ & $6.05 \mathrm{E}-05$ \\
\hline & & & 3143.087 & 3369.389 & $1.48 \mathrm{E}-05$ & 0.000297 \\
\hline & & & 3152.965 & 3379.978 & $5 \mathrm{E}-07$ & 9.3E-06 \\
\hline & & & 3213.368 & 3444.731 & 0.014575 & 264.7792 \\
\hline & & & 3215.866 & 3447.409 & 0.000127 & 0.006365 \\
\hline & & & 3219.81 & 3451.636 & 3.72146 & 115.9225 \\
\hline
\end{tabular}

${ }^{a}$ The calculated frequencies are multiplied by a scaling factor 1.072 . 

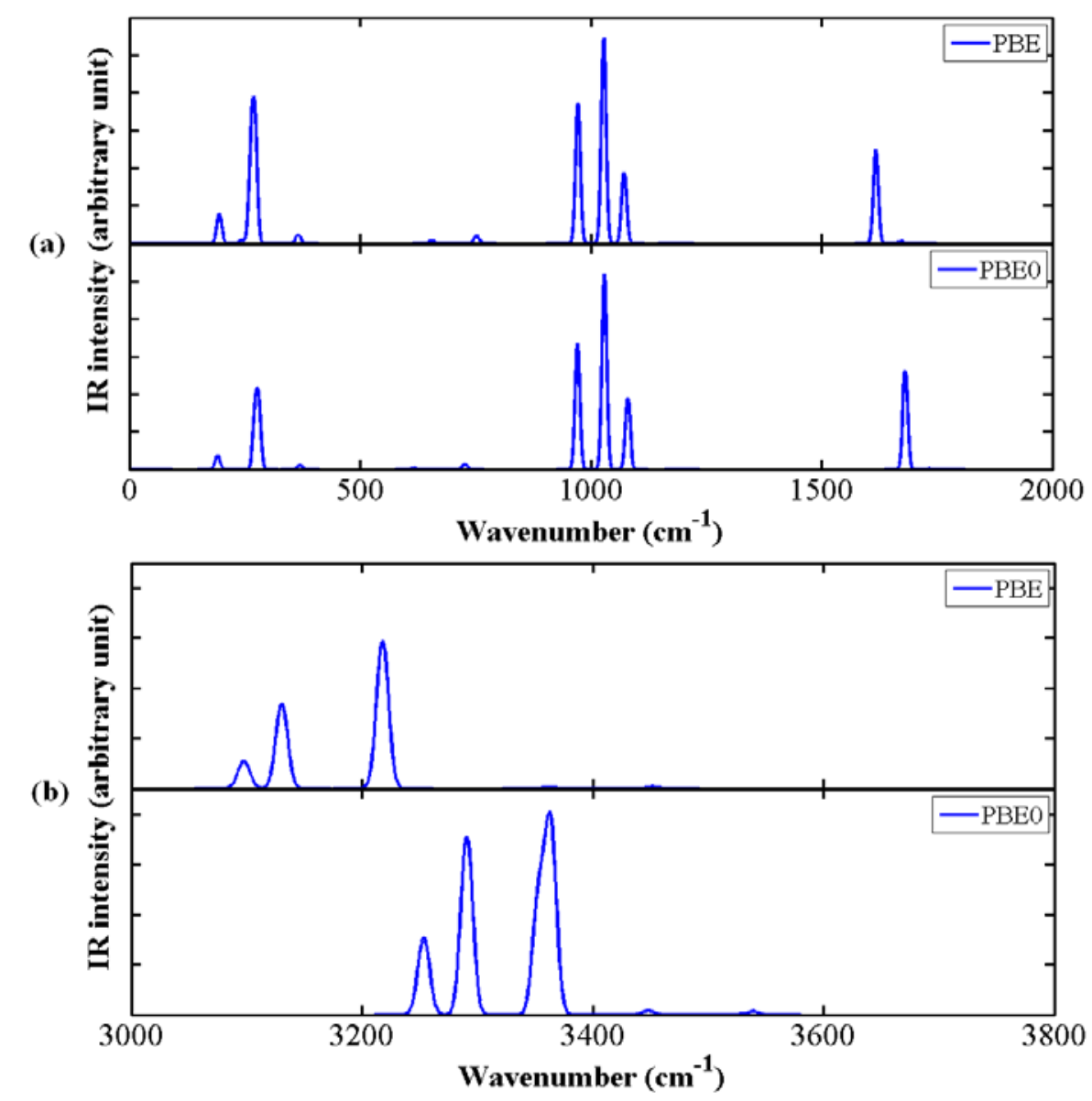

Figure S1. The IR spectra of ice XI computed using PBE (with plane wave basis set) and using PBE0 (with 6-311G(2d,2p) Gaussian basis set) methods: (a) the low frequency region and (b) the stretching vibration region. 

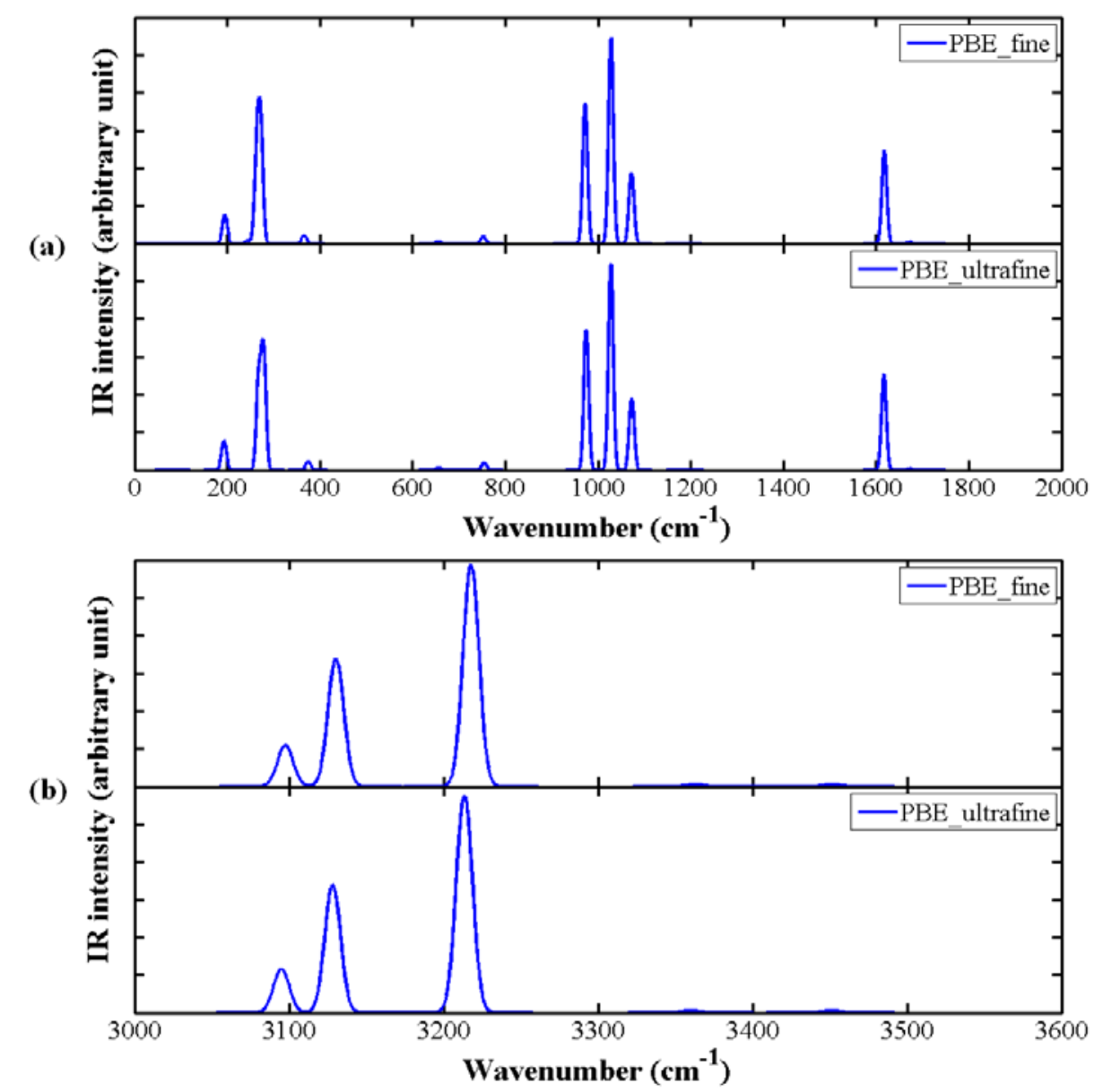

Figure S2. The IR spectra of ice XI computed using the PBE functional with the "fine" and the "ultrafine" settings in (a) the low frequency region and in (b) the stretching vibration region. For the "ultrafine" setting, the plane wave energy cutoff is $830 \mathrm{eV}$ and the k-point net is $6 \times 3 \times 3$. 

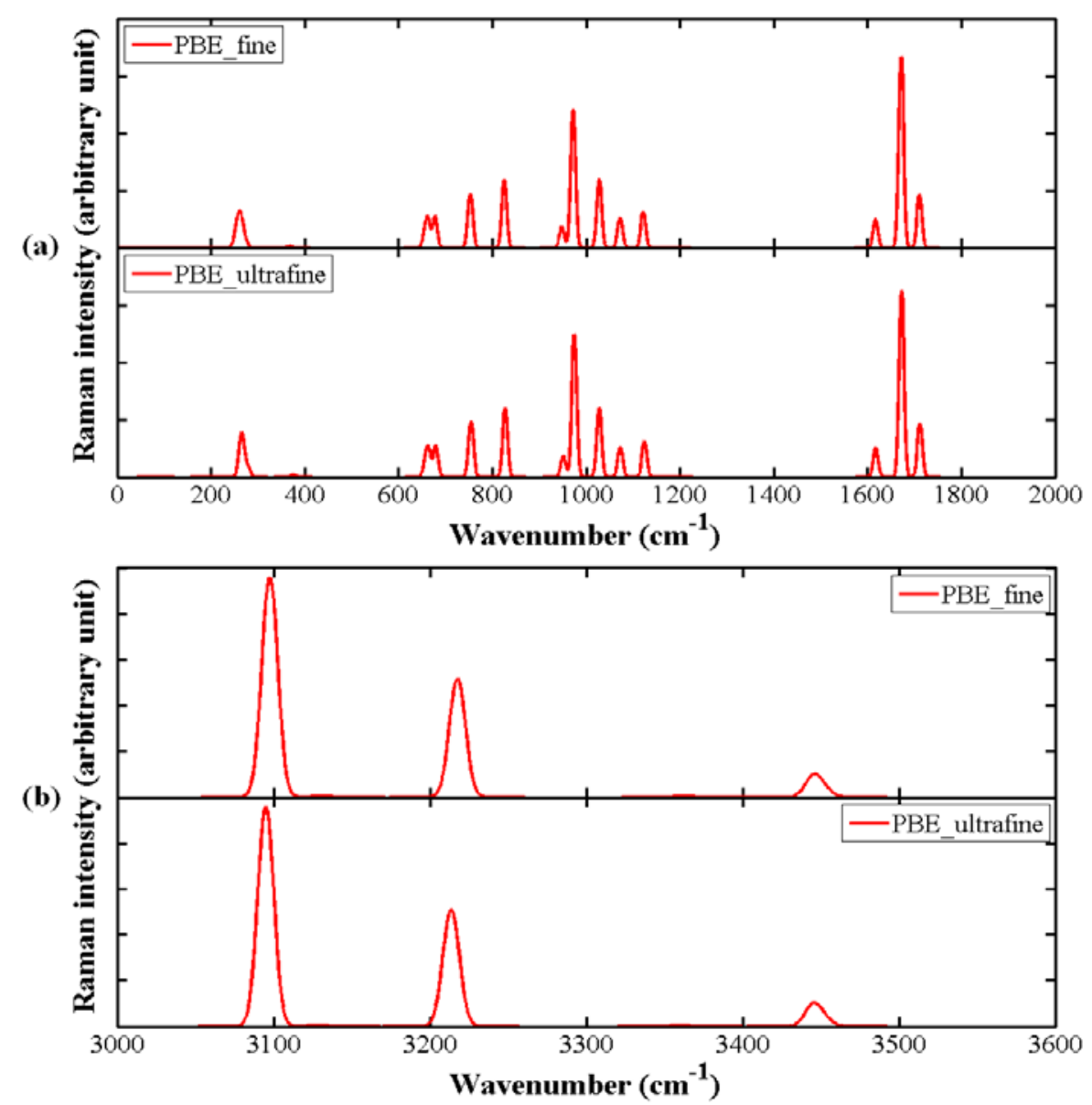

Figure S3. The Raman spectra of ice XI computed using the PBE functional with the "fine" and the "ultrafine" settings in (a) the low frequency region and in (b) the stretching vibration region. For the "ultrafine" setting, the plane wave energy cutoff is $830 \mathrm{eV}$ and the k-point net is $6 \times 3 \times 3$. 

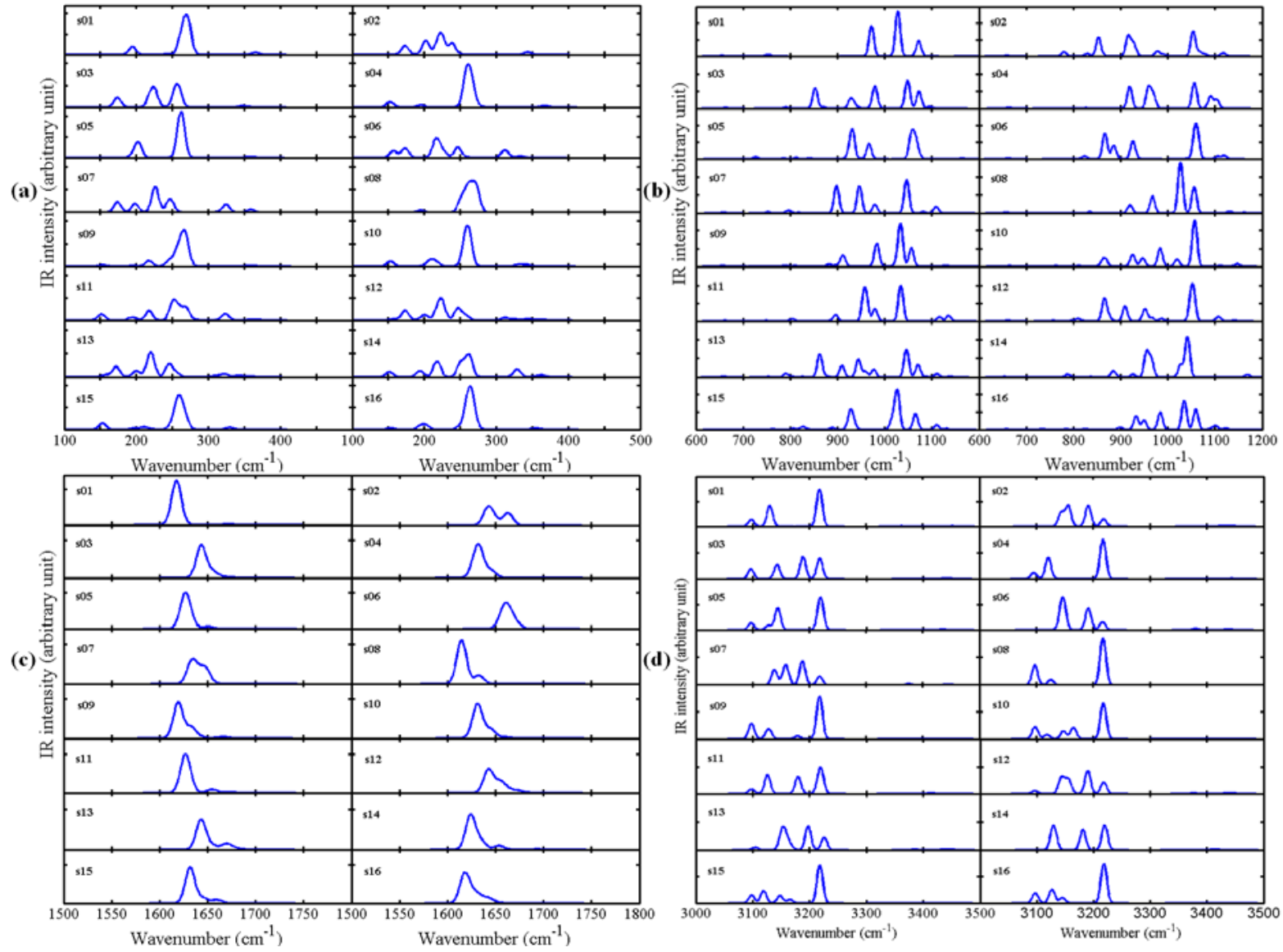

Figure S4. The IR spectra for the 16 proton-ordered structures of ice Ih: (a) translational modes, (b) librational modes, (c) bending modes, and (d) stretching modes. 
(a)
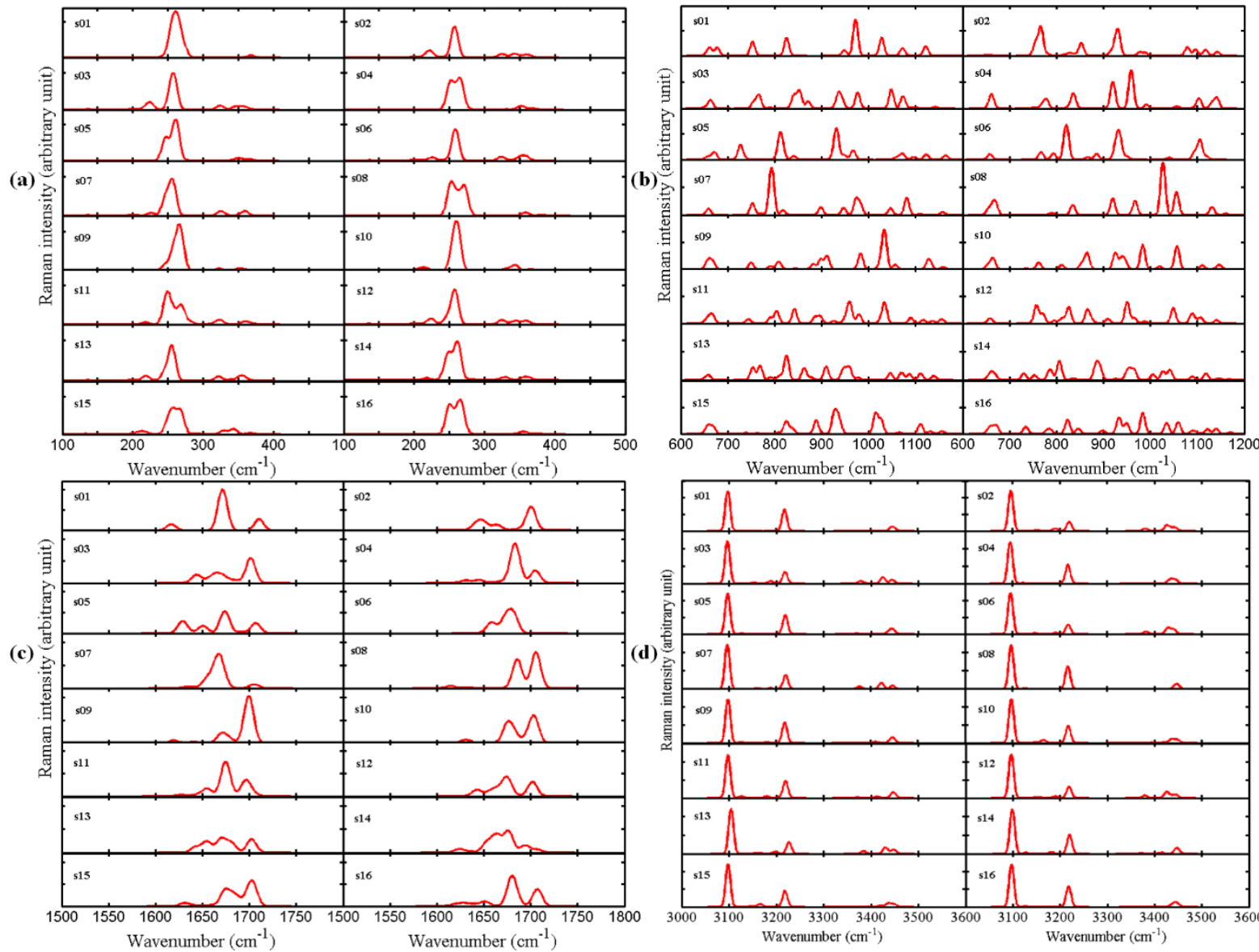

Figure S5. The Raman spectra for the 16 proton-ordered structures of ice Ih: (a) translational modes, (b) librational modes, (c) bending modes, and (d) stretching modes. 


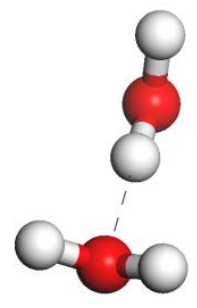

A

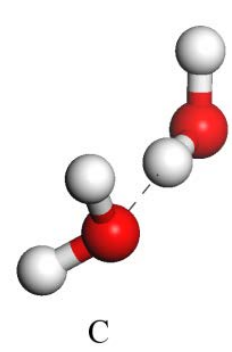

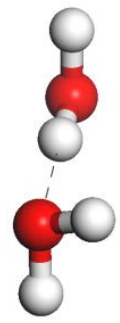

B

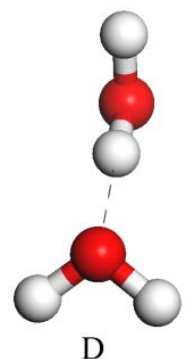

Figure S6. The H-bonded neighbor configuration geometries in ice Ih: A (h-cis), B (h-trans), C (c-cis), and D (c-trans). 